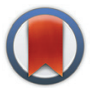

CrossMark

\&lick for updates

Cite this: Polym. Chem., 2017, 8, 24

Received 29th July 2016,

Accepted 3rd September 2016

DOI: 10.1039/c6py01320a

www.rsc.org/polymers

\title{
Thermoresponsive poly(2-oxazoline)s, polypeptoids, and polypeptides
}

\author{
Richard Hoogenboom ${ }^{\star a}$ and Helmut Schlaad ${ }^{\star b}$
}

This review covers the recent advances in the emerging field of thermoresponsive polyamides or polymeric amides, i.e., poly(2-oxazoline)s, polypeptoids, and polypeptides, with a specific focus on structurethermoresponsive property relationships, self-assembly, and applications.

\section{Introduction}

Natural systems are governed by adaptive and responsive behavior to survive, which is mostly driven by conformational changes and catalytic actions of proteins. These perfectly defined polyamide structures take on defined folded structures to get very sophisticated response behavior. Inspired by such

\footnotetext{
${ }^{a}$ Supramolecular Chemistry Group, Department of Organic and Macromolecular Chemistry, Ghent University, Krijgslaan 281 S4, B-9000 Ghent, Belgium. E-mail: richard.hoogenboom@ugent.be

${ }^{b}$ Institute of Chemistry, University of Potsdam, Karl-Liebknecht-Str. 24-25, 14476 Potsdam, Germany.E-mail:schlaad@uni-potsdam.de
}

systems, polymer scientists have developed a wide range of synthetic responsive polymer materials that respond to a wide range of stimuli $(\mathrm{pH}$, temperature, ionic strength, molecules, etc.) with various changes in the polymer materials, including phase transition, color change, and shape transformation. ${ }^{1}$

Thermoresponsive synthetic polymers that undergo a temperature induced solubility phase transition in aqueous solutions have received significant interest as mild temperature changes provide an easy way to trigger the solubility. ${ }^{2-8}$ Furthermore, such systems are highly appealing for development of drug delivery systems if the transition temperature is close to body temperature, allowing to prepare formulations that are soluble at room temperature and gel upon injection,

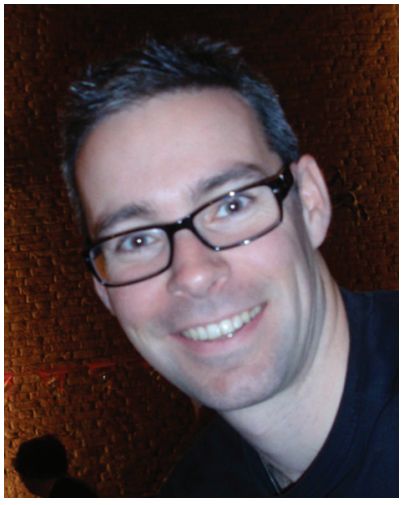

Richard Hoogenboom
Richard Hoogenboom (1978) studied chemical engineering at the Eindhoven University of Technology (the Netherlands). In 2005, he obtained his Ph.D. under the supervision of Ulrich S. Schubert and continued working as a project leader for the Dutch Polymer Institute. After postdoctoral training with Martin Moeller and Roeland Nolte, he was appointed as associate professor at Ghent University in 2010 and in October 2014 he was promoted to full professor. His research interests include stimuli-responsive polymers, supramolecular polymers, and poly(2-oxazoline)s. He has published more than 300 scientific articles and is currently associate editor for European Polymer Journal and Australian Journal of Chemistry. Prof. Hoogenboom is the recipient of the inaugural Polymer Chemistry Lectureship (2015) and the fifth PI IUPAC award (2016).

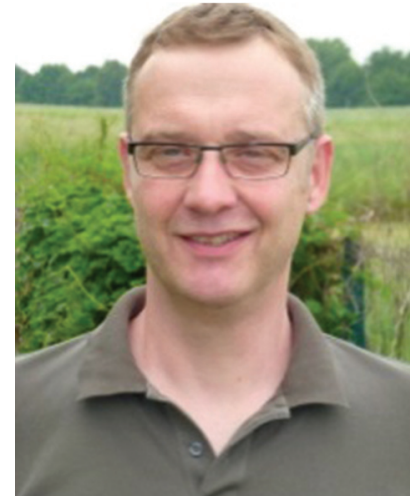

Helmut Schlaad
Helmut Schlaad (1967) studied chemistry at the University of Mainz (Germany) and earned a doctoral degree in Physical Chemistry, under Axel H. E. Müller in 1997. After one year post-doctoral fellowship with Rudolf Faust at the University of Massachusetts in Lowell (USA), he moved to the Max Planck Institute of Colloids and Interfaces in Potsdam (Germany). He finished habilitation in 2004, mentored by Markus Antonietti, and became professor in 2014 at the University of Potsdam. His research interests are directed towards polymer synthesis, bio-sourced polymers, smart functional materials, and bio-inspired polymer structures. He is currently an associate editor for Polymer International (Wiley). 
polymeric sensors as well as switchable surfaces. ${ }^{9-14}$ Two different types of thermoresponsive polymers exist, namely those that undergo a demixing phase transition upon heating and those that demix upon cooling.

Polymers that are fully soluble at low temperatures and phase separate upon heating are so-called lower critical solution temperature (LCST) polymers, whereby the LCST represents the lowest phase transition temperature in the entire binodal phase diagram. Most commonly, the cloud point temperature $\left(T_{\mathrm{cp}}\right)$ is reported as the phase separation temperature at a specific concentration, determined by turbidimetry. The LCST phase transition is driven by the entropy-loss due to interaction of water molecules with the polymer and upon heating this entropy-loss becomes dominant eventually leading to dehydration of the polymer and phase separation.

Polymers with opposite behavior are known as upper critical solution temperature (UCST) polymers and such behavior is much more rare as it is mostly based on the enthalpic attraction between the polymer chains. ${ }^{5}$ Such enthalpic attraction is based on supramolecular interactions, such as electrostatic interactions or hydrogen bonding. A second type of UCST polymer phase transition is more commonly observed in alcohol-water mixtures, which is driven by the non-ideal mixing of the solvent mixture leading to a significant drop in solvent polarity upon heating, thereby increasing the polymer solubility. ${ }^{7}$

Within this review, we provide an overview of recent work on synthetic thermoresponsive polyamides, or polymeric amides, that closely resemble the (random coil) structure of proteins, namely poly(2-oxazoline)s, polypeptoids, and polypeptides (Fig. 1). Synthetic polypeptides are analogues of natural peptides that are prepared by ring-opening polymerization of the corresponding amino acid $\mathrm{N}$-carboxyanhydrides, ${ }^{15}$ which are obviously not limited to the use of natural amino acids but allow the introduction of other functionalities to tune the thermoresponsive behavior. Polypeptoids are the tertiary amide analogues of polypeptides that can also be prepared by similar methods. Poly(2-oxazoline)s, prepared by living cationic ring-opening polymerization of 2-oxazolines, ${ }^{16,17}$ are polymers having tertiary amides units too, albeit with a slightly different configuration as only the nitrogen is part of the main chain and the carbonyl is part of the side chain. These three classes of polymes have in common that they have a hydrophilic main chain (partially) consisting of the repeating amide groups. As such, the introduction of slightly<smiles>[R]C(=O)N(C)CCC(C)(C)C</smiles>

Poly(2-oxazoline)<smiles>[R]N(C)CC(C)=O</smiles>

Polypeptoid

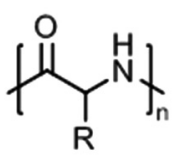

Polypeptide
Fig. 1 General chemical structures of (partially) main-chain polyamides: poly(2-oxazoline), polypeptoid, and polypeptide; $\mathrm{R}=$ organic substituent (usually alkyl). hydrophobic side chains allows accurate tuning of the hydrophilic-hydrophobic balance to obtain thermoresponsive polymers.

In the following, the recent developments in the areas of thermoresponsive poly(2-oxazoline)s (section 2.1), polypeptoids (section 2.2), and polypeptides (section 2.3) will be discussed mostly focusing on work from the past five years.

\section{Thermoresponsive polyamides or polymeric amides}

\subsection{Poly(2-oxazoline)s}

Poly(2-oxazoline)s are a synthetic class of polyamides, or polymeric amides, that are obtained by (living) cationic ringopening polymerization of 2-oxazoline monomers yielding the corresponding ring-opened polymers that have a tertiary amide structure of which just the nitrogen is incorporated in the polymer backbone. ${ }^{17-21}$ The 2-substituent of the monomer can be varied allowing accurate control over the hydrophilichydrophobic balance of the resulting poly(2-oxazoline)s. ${ }^{22-25}$ If the hydrophilic tertiary amide bond of the polymer backbone is complimented with small hydrophobic side chains, this leads to thermoresponsive poly(2-oxazoline)s with lower critical solution temperature (LCST) behavior. In this regard, the boundaries are set by poly(2-methyl-2-oxazoline), which is very hydrophilic and does not show LCST behavior in water, and by poly(2-butyl-2-oxazoline), in which the hydrophobic butyl side chains dominate the behavior making the polymer insoluble in water. Obviously, larger hydrophobic aliphatic or aromatic side chains also result in hydrophobic poly(2-oxazoline)s. Poly (2-oxazoline) homopolymers bearing side chains with intermediate hydrophobicity will lead to thermoresponsive polymers with LCST behavior in water. An overview of the poly (2-oxazoline) homopolymers that have been reported to exhibit LCST behavior is shown in Fig. 2.

2.1.1 Homopolymers. Poly(2-ethyl-2-oxazoline) (PEtOx; Fig. 2) was the first poly(2-oxazoline) analogue that was reported, in 1988 , to be thermoresponsive. Lin and coworkers reported $T_{\mathrm{cp}}$ values in between $61^{\circ} \mathrm{C}$ and $69^{\circ} \mathrm{C}$, depending on the molar mass and concentration of the polymer in water for rather high molar mass polymers. ${ }^{26}$ This study was extended to lower molar mass PEtOx by Du Prez et al. ${ }^{27}$ and later Schubert et $a .^{28}$ who demonstrated that PEtOx with minimal 100 repeat units is required to observe a $T_{\mathrm{cp}}$ below $100{ }^{\circ} \mathrm{C}$. It was also demonstrated that PEtOx follows classical Flory-Huggins type 1 behavior, that is the $T_{\mathrm{cp}}$ decreases with increasing molar mass. The LCST of PEtOx, defined as the lowest $T_{\mathrm{cp}}$ in the polymer-water phase diagram has been reported to be around $60{ }^{\circ} \mathrm{C}$ to $63^{\circ} \mathrm{C} .{ }^{26}$ The architecture of the PEtOx also has a significant impact on the thermoresponsive behavior as enforcing a higher local polymer concentration, by attachment of short PEtOx fragments to a compact core structure, leads to a significant drop in $T_{\mathrm{cp}}$. This effect has been demonstrated by Dworak et al. for star-shaped PEtOx, which had a $T_{\text {cp }} 62^{\circ} \mathrm{C}$ while a linear analogue had a $T_{\text {cp }}$ of $75^{\circ} \mathrm{C} . .^{29}$ 


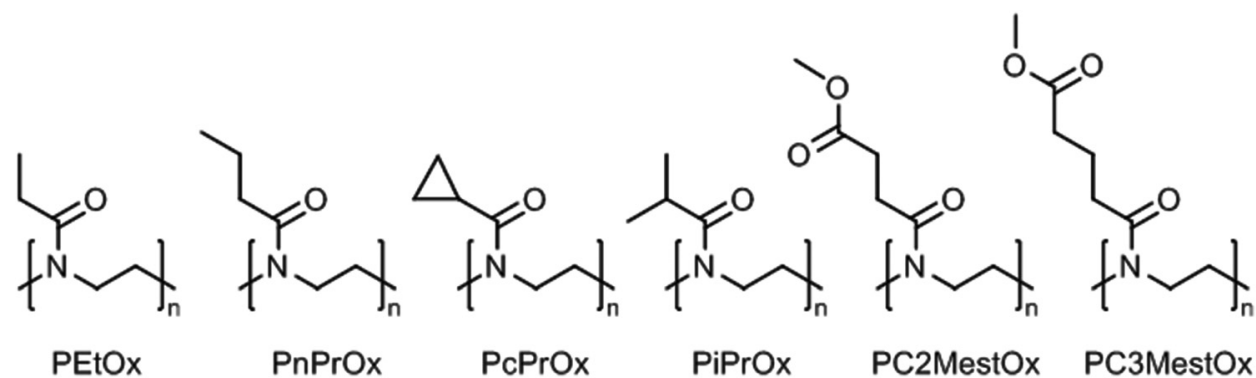

Fig. 2 Thermoresponsive poly(2-oxazoline) homopolymers with the abbreviated names.

A recent report by Grayson described the straightforward synthesis of cyclic poly(2-oxazoline)s, ${ }^{30}$ and albeit no thermoresponsive properties have been reported yet, it may be anticipated that cyclic poly(2-oxazoline)s will have different thermoresponsivity compared to their linear analogues as has been reported for poly( $N$-isopropylacrylamide) (PNIPAM) ${ }^{31}$ The high local concentration of PEtOx in amphiphilic block copolymer micelles also leads to a drop in $T_{\mathrm{cp}}$ to around $60{ }^{\circ} \mathrm{C},{ }^{32}$ while PEtOx-functionalized peptide nanotubes had a $T_{\mathrm{cp}}$ of $70{ }^{\circ} \mathrm{C}$ and the degree of polymerization (DP) of PEtOx was only $40 .{ }^{33}$ Similarly, a comb-shaped polymer having short PEtOx with DP of five in the side chain of a polymethacrylate backbone was reported by Schubert to have a LCST of $75{ }^{\circ} \mathrm{C}$ based on determination of the complete coexistence curve. $^{34}$ Furthermore, the effect of both Hofmeister salts and ions has been demonstrated as tool for tuning of the $T_{\mathrm{cp}}$ in the entire range from $0{ }^{\circ} \mathrm{C}$ to $100{ }^{\circ} \mathrm{C}$ by Hoogenboom et al. ${ }^{35}$ Demirel et al. ${ }^{36}$ and Schlaad et al. ${ }^{37}$ Even though, it is generally accepted that the temperature induced LCST phase transition of poly(2-oxazoline)s has little to no hysteresis, in contrast to the widely studied PNIPAM, ${ }^{38}$ Demirel has demonstrated that prolonged annealing of an aqueous solution of PEtOx above the $T_{\mathrm{cp}}$ leads to irreversible crystallization and formation of nanofibers. ${ }^{39}$

Poly(2-isopropyl-2-oxazoline) (PiPrOx; Fig. 2) was first reported to be thermoresponsive by Uyama and Kobayashi in $1992 .{ }^{40}$ As the LCST of PiPrOx is close to body temperature, being $26{ }^{\circ} \mathrm{C}$ to $34{ }^{\circ} \mathrm{C}$ depending on polymer molar mass indicative of type 1 Flory-Huggins behavior, ${ }^{41}$ this polymer has developed into the most studied and most popular thermoresponsive poly(2-oxazoline) derivative. ${ }^{42-44}$ Similar to PEtOx, Filippov and coworkers demonstrated for PiPrOx that the $T_{\text {cp }}$ decreases for star-shaped polymers compared to linear analogues due to enhanced local polymer concentration and polymer-polymer interactions. ${ }^{45}$ PiPrOx comb-shaped polymers were demonstrated by Jordan to have $T_{\mathrm{cp}}$ 's of $28{ }^{\circ} \mathrm{C}$ to $31{ }^{\circ} \mathrm{C}$ with side chain graft lengths down to DP 4 units indicating that the high local concentration induces the thermoresponsive behavior since linear PiPrOx with DP 17 has been reported to have a $T_{\mathrm{cp}}$ of $73{ }^{\circ} \mathrm{C} .{ }^{42,46}$ Furthermore, the $T_{\mathrm{cp}}$ of PiPrOx has been demonstrated to strongly depend on the endgroup, especially for shorter polymer chains where the effect of the end-group is more dominant. Winnik et al. reported that the $T_{\text {cp }}$ of PiPrOx with DP 57 decreased from $48.1^{\circ} \mathrm{C}$ with methyl and hydroxyl end-groups to $32.5{ }^{\circ} \mathrm{C}$ with $n$-octadecyl and hydroxyl end-groups and $31.6{ }^{\circ} \mathrm{C}$ with two $n$-octadecyl end-groups (all at $0.1 \mathrm{mg} \mathrm{mL}^{-1}$ in water) ${ }^{47}$ A detailed investigation by high sensitivity differential scanning calorimetry revealed that both polymers with one and two $n$-octadecyl endgroups organized into micellar aggregates, thereby leading to similar enhanced polymer-polymer interactions and similar $T_{\mathrm{cp}}$ values. Similar results were reported by Jordan who demonstrated that the $T_{\mathrm{cp}}$ of PiPrOx with DP 27 decreased from $47^{\circ} \mathrm{C}$ to $28{ }^{\circ} \mathrm{C}$ and $32{ }^{\circ} \mathrm{C}$ by introduction of one or two $n$-nonyl end-groups, respectively (all at $20 \mathrm{mg} \mathrm{mL}^{-1}$ ), tentatively ascribed to micellization. ${ }^{48}$ Furthermore, it was demonstrated that introduction of short hydrophilic PMeOx outer blocks with DP 3 increased the $T_{\text {cp }}$ to $53{ }^{\circ} \mathrm{C}$ while introducing short hydrophobic poly(2-n-nonyl-2-oxazoline) outer blocks with DP 1 or DP 2 decreased the $T_{\mathrm{cp}}$ to $15{ }^{\circ} \mathrm{C}$ and $11^{\circ} \mathrm{C}$.

Even though all the early reports on the LCST behavior of PiPrOx demonstrated fully reversible phase transitions without significant hysteresis, Schlaad and coworkers were the first to report irreversible crystallization driven self-assembly of PiPrOx upon continued heating above the $T_{\mathrm{cp}}{ }^{49-51}$ In 2012, Winnik and coworkers demonstrated by a combination of optical spectroscopy and solution vibrational spectroscopy and molecular dynamics simulations that heating of PiPrOx aqueous solution leads to an irreversible change in the chain conformation to a more regular all-trans conformation (Fig. 3) ${ }^{52}$ Despite this change in chain conformation, the LCST phase transition remains fully reversible upon repetitive heating-cooling cycles. However, prolonged heating leads to crystallization facilitated by the more regular chain conformation. This hypothesis was more recently confirmed by the work of Wu based on temperature variable ${ }^{1} \mathrm{H}$ NMR, Fouriertransform infrared and Raman spectroscopy, including twodimensional correlation spectroscopy. ${ }^{53}$

Only 15 years after the first report on the LCST behavior of PiPrOx, Kataoka and coworkers reported that poly(2-n-propyl-2oxazoline) (PnPrOx; Fig. 2) also exhibits LCST behavior with a $T_{\mathrm{cp}}$ around $25{ }^{\circ} \mathrm{C} .{ }^{54}$ The $T_{\mathrm{cp}}$ of PnPrOx revealed much smaller molar mass and concentration dependence than PEtOx as may be attributed to its more hydrophobic character that facilitates dehydration. ${ }^{28}$ The third possible $\mathrm{C}_{3}$ side chain, 

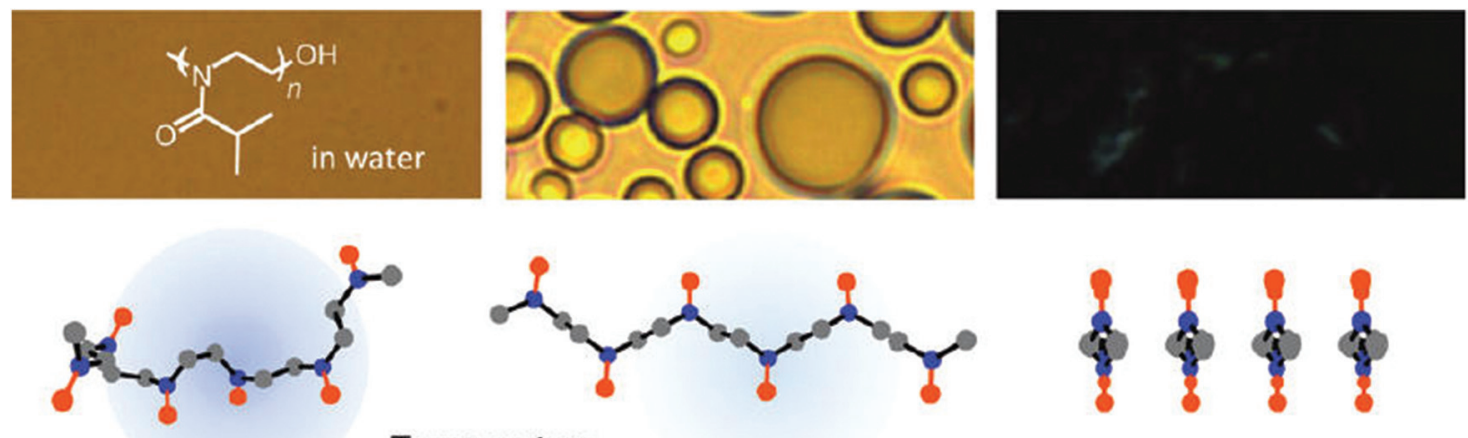

Temperature
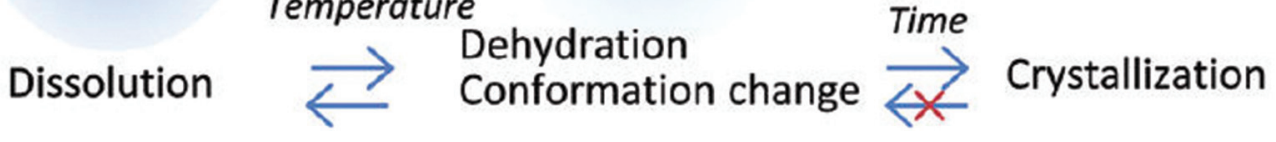

Time

Fig. 3 Proposed mechanism for the irreversible crystallization of PiPrOx upon annealing of aqueous solutions above the cloud point temperature. Reprinted with permission from ref. 52. Copyright 2012 American Chemical Society.

namely cyclopropyl, was reported by Schubert et al. to lead to poly(2-cyclopropyl-2-oxazoline) (PcPrOx; Fig. 2), which is also thermoresponsive and has a $T_{\mathrm{cp}}$ that is intermediate to PiPrOx and PnPrOx. ${ }^{55}$ For both PnPrOx and PcPrOx it has been demonstrated that incorporation as side chains in comb polymers leads to a decrease in $T_{\mathrm{cp} .}{ }^{46,55}$

Poly(2-oxazoline)s with methyl ester side chains were first reported by Litt in $1968,{ }^{56}$ but it was only reported in 2015 by Hoogenboom that such polymers exhibit thermoresponsive LCST behavior in aqueous solution. ${ }^{57}$ In fact, poly(2-methoxycarbonylethyl-2-oxazoline) (PC2MestOx; Fig. 2) has very similar solution behavior as PEtOx with a $T_{\mathrm{cp}}$ around $100{ }^{\circ} \mathrm{C}$ for a polymer with DP 100 while poly(2-methoxycarbonylpropyl-2oxazoline) (PC3MestOx; Fig. 2) has very similar behavior as PnPrOx with a $T_{\mathrm{cp}}$ around $25^{\circ} \mathrm{C}$.

2.1.2 Homopolymer mixtures. A rather recent trend in tuning of thermoresponsive behavior of polymers is by mixing (also referred to as blending) of polymers, sometimes leading to cooperative behavior. ${ }^{58-61} \mathrm{Wu}$ and coworkers reported a study on mixing of PiPrOx with PNIPAM and poly( $N$-vinylcaprolactam) (PNVCL). ${ }^{62}$ Rather strikingly it was observed that mixtures of PiPrOx and PNIPAM undergo two distinct phase transitions that are slightly affected by the presence of the other polymer, while mixtures of PiPrOx and PNVCL undergo one cooperative phase transition. This difference in behavior upon mixing was ascribed to the strong intramolecular hydrogen bonding of PNIPAM that does not allow interactions with PiPrOx. On the other hand PiPrOx and PNVCL are both polymers with only hydrogen bond accepting amide groups and upon heating water bridges are formed between the two polymers leading to cooperative phase separation and the formation of a high concentration phase containing both polymers. However, Zhang and coworkers reported that mixtures of poly(methyl vinyl ether) and PEtOx also revealed two distinct phase transitions while both polymers only contain hydrogen accepting groups, ${ }^{63}$ indicating that the rationale between cooperative LCST behavior is not yet well understood. Further work of Trzebicka and coworkers on mixtures of PNIPAM and PiPrOx revealed the influence of heating rate on the thermoresponsiveness. ${ }^{64}$ Slow gradual heating, as is commonly applied during turbidimetry, indeed confirmed two distinct phase transitions of the individual polymers. In contrast fast sudden temperature increase above the $T_{\mathrm{cp}}$ of both polymers led to the formation of mixed phase separated mesoglobules, a term used to describe the high concentrated dispersed polymer phase that is formed upon crossing the phase transition temperature of dilute polymer solutions. A study on mixing of poly (2-oxazoline)s bearing a hydrophobic lipid chain that selfassemble into micelles in water was reported by Morandi et al. ${ }^{65}$ Both PEtOx and PiPrOx were synthesized using a tosylate functionalized lipid initiator and the resulting polymers with $T_{\text {cp }}$ of $35{ }^{\circ} \mathrm{C}$ and $76{ }^{\circ} \mathrm{C}$, respectively, were subsequently mixed at different ratios in aqueous solution. Up to addition of $52 \%$ of lipid-PEtOx, the $T_{\text {cp }}$ gradually increased from $35{ }^{\circ} \mathrm{C}$ to $42{ }^{\circ} \mathrm{C}$, but at higher lipid-PEtOx content two distinct phase transitions were observed, one corresponding to cooperative behavior and one corresponding to pure lipid-PEtOx. The authors did not yet unravel whether this behavior results from the presence of mixed micelles and pure PEtOx micelles already below the $T_{\mathrm{cp}}$ or that demixing of PEtOx and PiPrOx occurred during the LCST phase transition.

2.1.3 Statistical copolymers. The previously discussed mixing approach is an interesting and straightforward way of tuning $T_{\mathrm{cp}}$, albeit it is hard to predict whether or not cooperative behavior will be obtained. A more robust way of accurately tuning the $T_{\mathrm{cp}}$ of poly(2-oxazoline)s is by copolymerizing different monomers to accurately control the hydrophilichydrophobic balance of the copolymer chains. $T_{\mathrm{cp}}$ values are adjustable between $0{ }^{\circ} \mathrm{C}$ and $100{ }^{\circ} \mathrm{C}$ by incorporation of inert more hydrophobic or more hydrophilic comonomers into one of the discussed thermoresponsive homopolymer, respectively. Specific examples of copolymers with tunable $T_{\mathrm{cp}}$ include copolymers of PEtOx with PnPrOx ${ }^{22,54}$ PiPrOx,${ }^{66}$ PcPrOx,${ }^{67}$ and poly(2-n-nonyl-2-oxazoline) (PNonOx), ${ }^{68,69}$ copolymers of 
PiPrOx with PEtOx ${ }^{66}$ PnPrOx,${ }^{54,68}$ poly(2-n-butyl-2-oxazoline) (PButOx), ${ }^{68}$ and PNonOx ${ }^{68}$ as well as copolymers of PnPrOx with PMeOx, ${ }^{70}$ PEtOx, ${ }^{22,54}$ and PiPrOx. ${ }^{54,68}$

In recent years, some more exotic comonomers have been explored to tune the $T_{\mathrm{cp}}$ of poly(2-oxazoline)s in aqueous solution. Volet and coworkers reported copolymers of PMeOx and poly(2-(5-azidopentyl)-2-oxazoline) that have $T_{\mathrm{cp}}$ values in between $0{ }^{\circ} \mathrm{C}$ and $100{ }^{\circ} \mathrm{C}$ depending on the comonomer composition. ${ }^{71}$ Schubert et al. reported the synthesis of copolymers of PEtOx and poly(2-(4-Boc-aminobutyl)-2-oxazoline) (Boc = tert-butyloxycarbonyl) that after removal of the Boc group yielded copolymers of PEtOx and poly(2-(4-aminobutyl)-2oxazoline). ${ }^{72}$ Even though the amino group is more hydrophilic in water due to protonation leading to fully water-soluble copolymers that do not show LCST behavior in neutral water, it was demonstrated that at $\mathrm{pH} \mathrm{14}$, where the amino-group is in its free base form, the copolymers had $T_{\mathrm{cp}}$ values in between $25{ }^{\circ} \mathrm{C}$ and $65{ }^{\circ} \mathrm{C}$, depending on the copolymer composition and the polymer concentration. Copolymers of PEtOx, PnPrOx, PC2MestOx and PC3MestOx were also shown to have tunable $T_{\mathrm{cp}}$ values in between $25^{\circ} \mathrm{C}$ and $100{ }^{\circ} \mathrm{C} .{ }^{57}$ Interestingly, copolymers of PEtOx and PC3MestOx revealed a linear relationship between composition and $T_{\mathrm{cp}}$ while copolymers of PnPrOx and PC2MestOx cover exactly the same range of $T_{\mathrm{cp}}$ values, but with a strong non-linear correlation. This difference in behavior is not yet understood, but may be related to the size of the side chains and their exposure to the aqueous phase. Hydrolysis of PcPrOx-PC2MestOx and PnPrOx-PC2MestOx copolymers was demonstrated to lead to dual responsive polymers that are sensitive to both temperature and $\mathrm{pH}$ resulting from (de)protonation of the carboxylic acid units. ${ }^{73,74}$ Similarly, direct amidation of the PC2MestOx with ethylene diamine led to an amine functional copolymer showing temperature and $\mathrm{pH}$ sensitivity based on (de)protonation of the amino groups. ${ }^{73,75}$ Schlaad and coworkers reported dual responsive poly(2-oxazoline) micelles containing carboxylic acid or amine groups in the core, prepared by post-polymerization modification of core-crosslinked micelles using thiol-yne radical coupling. ${ }^{32}$ These ionically modified crosslinked micelles were demonstrated to not only respond to changes in temperature and $\mathrm{pH}$, but their $T_{\mathrm{cp}}$ values were also strongly dependent on the presence of salts following the Hofmeister series. ${ }^{37}$

These latter examples already indicated that post-polymerization modification is another popular strategy to control the $T_{\mathrm{cp}}$ of poly(2-oxazoline)s. The popularity of this strategy is based on the possibility to modify the side chains of (co)polymers without affecting the polymer chain length and molar mass distribution allowing direct interpretation of the effect of the side chain on the $T_{\mathrm{cp}}$. Schlaad et al. introduced poly (2-butenyl-2-oxazoline) (PButenOx) as a robust scaffold for post-polymerization modification using radical thiol-ene chemistry. ${ }^{76,77}$ This methodology was then applied for postpolymerization modification of PiPrOx-PButenOx copolymers to tune the $T_{\mathrm{cp}}$ providing a versatile platform in which the $T_{\mathrm{cp}}$ could be tuned by copolymer composition as well as by post-polymerization modification. ${ }^{78}$ As expected, introduction of hydrophobic side chains such as acetyl-protected thioglucose and 1-octanethiol led to a decrease in $T_{\mathrm{cp}}$, whereas introduction of hydrophilic side chains such as 2-mercaptoethanol and 1-thioglycerol increased the $T_{\mathrm{cp}}$. Similarly, deprotection of the acetyl-glucose side chains led to significant increase in $T_{\mathrm{cp}}$. Schubert and coworkers reported a very similar strategy for the post-polymerization modification of PEtOx-poly(2-(9-decenyl)-2-oxazoline) (PEtOx-PDecenOx) copolymers. ${ }^{79}$ However, the presence of the long hydrophobic alkyl side chain led to a decrease in $T_{\mathrm{cp}}$ when unprotected thioglucose was attached to the terminal double bonds by thiol-ene coupling. ${ }^{80}$ This difference in behavior between the PButenOx and PDecenOx can be ascribed to the formation of hydrophobic pockets that favor hydrogen bonding between the glucose and the amide groups of the polymer backbone in the case of PDecenOx ${ }^{81}$ thereby enhancing the polymer-polymer interactions and decreasing the solubility. A final example of tuning the $T_{\mathrm{cp}}$ by post-polymerization modification of poly (2-oxazoline)s was reported by Meier and Hoogenboom et al. making use of Passerini and Ugi multicomponent side chain modification of an acid-containing copolymer obtained by hydrolysis of PEtOx-PC3MestOx. ${ }^{82}$ By variation of the small molecule reagents for these multicomponent reactions, the $T_{\mathrm{cp}}$ of the acid-functionalized copolymer $\left(T_{\mathrm{cp}}=78^{\circ} \mathrm{C}\right)$ could be lowered to $15{ }^{\circ} \mathrm{C}$ while intermediate transition temperatures could also be achieved.

2.1.4 Block copolymers. As mentioned previously, adding short hydrophilic or hydrophobic blocks to a thermoresponsive poly(2-oxazoline) can be exploited to modify the $T_{\mathrm{cp}}$ of the polymer. ${ }^{48}$ A longer hydrophilic block can also be utilized to develop thermoresponsive micelles that are fully soluble below the $T_{\mathrm{cp}}$ and assemble into micellar nanostructures upon heating. This concept has been utilized by Hruby and coworkers by developing a triblock copolymer consisting of hydrophilic PMeOx outer blocks and middle thermoresponsive block consisting of a statistical copolymer of PiPrOx and PButOx. ${ }^{83}$ Upon increasing the temperature, this triblock copolymer self-assembled into defined micellar structures. Kataoka and Jang prepared a block copolymer consisting of a poly(benzyl ether) dendron with carboxylic acid moieties at the periphery as one block and PiPrOx as thermoresponsive second block. ${ }^{84}$ This system showed intricate self-assembly behavior that could be controlled by both temperature and $\mathrm{pH}$ to lead to unimolecularly dissolved chains at high $\mathrm{pH}$ below $T_{\mathrm{cp}}$, vesicular structures at high $\mathrm{pH}$ above $T_{\mathrm{cp}}$, cylindrical micelles at low $\mathrm{pH}$ below $T_{\mathrm{cp}}$ and macroscopic aggregates at low $\mathrm{pH}$ above $T_{\mathrm{cp}}$. A block copolymer consisting of PiPrOx as thermoresponsive block and poly(3-acrylamidopropyltrimethylammonium chloride) as permanently charged hydrophilic block was reported by Winnik et al. ${ }^{85}$ Upon increasing the temperature of an aqueous solution of this block copolymer above the $T_{\mathrm{cp}}$ of PiPrOx of $40{ }^{\circ} \mathrm{C}$ the block copolymer selfassembled into vesicular structures. However, depending on the heating rate, the pathway to form these structures was found to vary. Fast heating from room temperature to $60{ }^{\circ} \mathrm{C}$ 
led to initial assembly into cylindrical micelles that rearranged into vesicles, while slow heating led to the initial formation of small spheres that slowly grew in size upon further heating until diffusion of the hydrophilic charged block to the center leads to the formation of the vesicles.

A double thermoresponsive PEtOx- $b$-PnPrOx block copolymer was reported by Hoogenboom and Kjoniksen et al. ${ }^{86}$ The thermoresponsive behavior of this block copolymer was studied by a combination of static and dynamic light scattering and turbidimetry revealing that below the $T_{\mathrm{cp}}$ of both blocks the polymer is present as unimers and in loose aggregates (Fig. 4). When passing the $T_{\mathrm{cp}}$ of the PnPrOx block, large aggregates are formed that upon further heating undergo a transition to defined micellar aggregates with a PnPrOx core and a PEtOx corona. Further heating beyond the $T_{\mathrm{cp}}$ of PEtOx led to the formation of large macroscopic aggregates as the entire polymer becomes insoluble in water. A related study on PEtOx- $b$-PiPrOx block copolymers was reported by Sato and Winnik et al. ${ }^{87}$ Upon heating the block copolymer solution in water to $50{ }^{\circ} \mathrm{C}$, which is in between the $T_{\text {cp }}$ of both individual blocks, the initial formation of star-like micelles was observed that further aggregate to induce macroscopic phase segregation. This is in contrast to the PEtOx- $b$-PnPrOx block copolymer micelles that remained stable in time, which may be ascribed to the smaller difference in $T_{\mathrm{cp}}$ of PEtOx and PiPrOx leading to more cooperative behavior compared to PEtOx and PnPrOx. Similarly, PiPrOx- $b$-PNIPAM block copolymers were also reported to undergo one cooperative phase separation rather than individual collapse of the blocks. ${ }^{88}$

2.1.5 UCST-type polymers. In contrast to this large amount of work on LCST-type poly(2-oxazoline)s, only a limited number of studies reported UCST-type poly(2-oxazoline)s in alcohol-water solvent mixtures and no poly(2-oxazoline) has been reported with UCST behavior in pure water. Such UCSTtype solubility in alcohol-water mixtures can be obtained by increasing the hydrophobicity of the side chain resulting in insolubility in water as well as alcohol-water solvent mixtures. However, these latter solvent mixtures will become less polar upon heating allowing dissolution of the polymer as has been demonstrated by Schubert and Hoogenboom et al. for PButOx, being the least hydrophobic water-insoluble poly(2-oxazoline). ${ }^{89}$ While PButOx revealed UCST behavior in 50:50 wt $\%$ ethanol-water solvent mixtures, more and more ethanol was required to get such behavior if the side chain length was increased up to PNonOx. ${ }^{89}$ A broad screening of the effect of poly(2-oxazoline) side chain on the LCST and UCST behavior in ethanol-water solvent mixtures revealed a general correlation between hydrophobicity and required amount of ethanol to gain UCST behavior (Fig. 5). Besides control over the UCST behavior by variation of the 2-oxazoline monomer structure, it can also be controlled by copolymerization of different monomers as was demonstrated for PEtOx-NonOx random copolymers. ${ }^{69}$

Annealing of poly(2-isobutyl-2-oxazoline) (PiBuOx) and PNonOx below their UCST in ethanol-water solvent mixtures was demonstrated by Schlaad and coworkers to lead to isothermal crystallization leading to nanosized hierarchically orga-

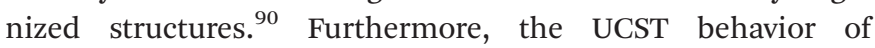
PPhOx in ethanol-water solvent mixtures was exploited by Schubert et al. for the preparation of thermoresponsive micelles consisting of PMeOx or PEtOx as hydrophilic part and PPhOx as UCST-switchable part. ${ }^{91}$ The resulting micelles that are formed below the UCST phase transition temperature dissolve into unimoleculaly dissolved polymer chains upon heating. Another example of UCST-switchable micelles was reported by Hoogenboom et al. based on copolymers of PNonOx and PPhOx. ${ }^{92}$ By variation of the solvent system, one single copolymer was found to form UCST switchable micelles with either PNonOx as switchable core or PPhOx as switchable core.

2.1.6 Applications. Temperature responsive poly(2-oxazoline)s are already known since 1988 and in recent years their application potential is being explored more and more. In the following, some recent application directed studies based on responsive poly(2-oxazoline)s will be discussed. The temperature induced self-assembly of poly(2-oxazoline)s has most frequently been used to exploit the size and shape of the formed mesoglobules or micelles in the case double hydrophilic diblock copolymers are used that contain a permanently soluble block and a thermoresponsive block. Hruby and
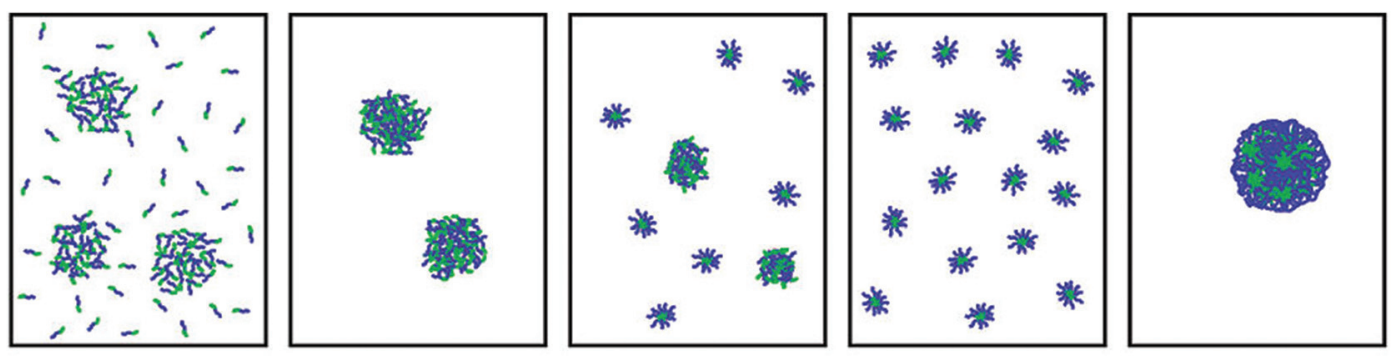

Increasing Temperature

Fig. 4 Schematic representation of the temperature induced self-assembly of PEtOx- $b$-PnPrOx going from a mixture of unimers and loose aggregates below $T_{\mathrm{cp}}$ to large aggregates that fall apart in discrete and defined micelles with a PnPrOx core and PEtOx corona until finally macroscopic aggregation when passing the $T_{\mathrm{cp}}$ of PEtOx. Reprinted with permission from ref. 86. Copyright 2012 American Chemical Society. 

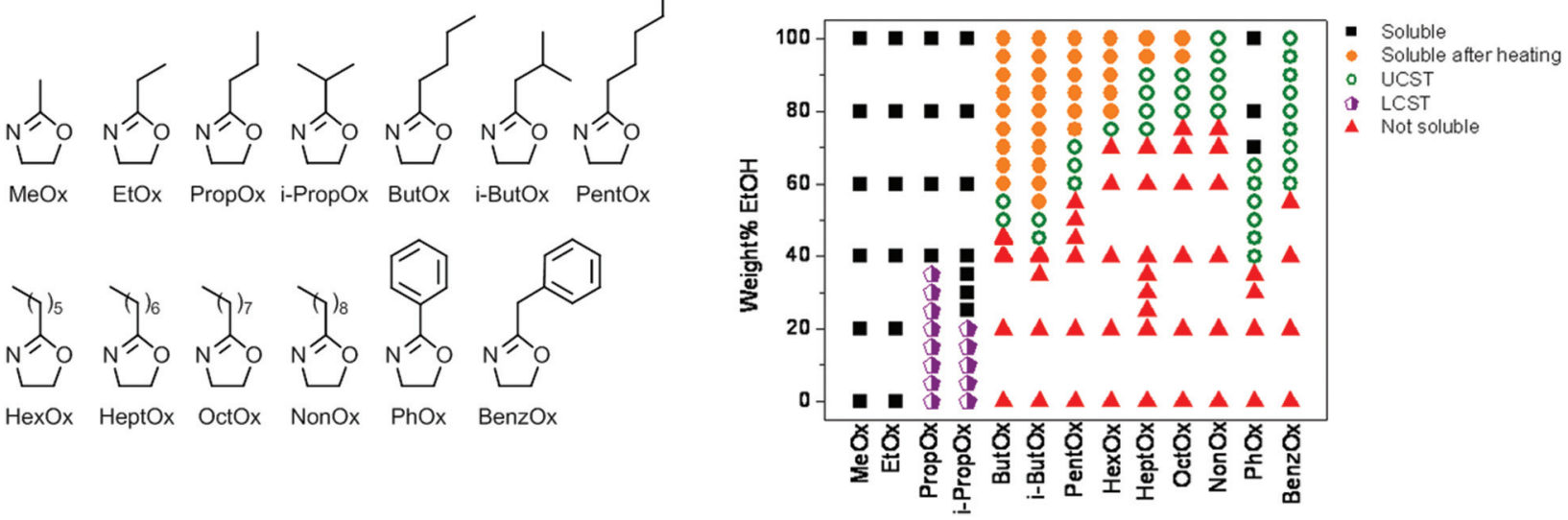

Fig. 5 Screening of solubility behavior of a wide set of poly(2-oxazoline)s (monomer structures shown) (left) in different ethanol-water solvent mixtures (right). Reprinted with permission from ref. 89. Copyright 2010 MDPI AG.

coworkers used this feature in PMeOx-b-(PiPrOx-stat-PButOx)$b$-PMeOx triblock copolymers that were labeled with ${ }^{125}$ iodine as radionuclide. ${ }^{83}$ Upon increasing the temperature, radionuclide loaded micelles are formed due to collapse of the middle block that could benefit from the enhanced permeation and retention effect for passive targeting of nanocarriers to tumors. It was also demonstrated the PiPrOxPButOx copolymers are more stable against small doses of $\beta$-radiation than other potential thermoresponsive polymers for therapeutics, including PNIPAM and PNVCL. ${ }^{93}$

In a related context, Osada and Kataoka et al. reported a triblock copolymer consisting of PEtOx, PnPrOx as middle thermoresponsive block and polylysine as cationically charged block. ${ }^{94}$ The polylysine could be exploited for complexation with DNA resulting in cylindrical micelle self-assembled structures. Increasing the temperature of the solution then led to collapse of the PnPrOx block onto the DNA-polylysine core, thereby providing a barrier to stabilize the polyplex on the one hand and to protect the DNA against degradation on the other hand. This novel strategy was demonstrated to lead to enhanced transfection efficiency.

The formation of defined mesoglobules upon increasing the temperature of an aqueous solution of PiPrOx was utilized by Rangelov et al. as template for the construction of hollow capsules. ${ }^{95}$ The collapsed mesoglobules of PiPrOx were utilized as seeds for the radical polymerization of NIPAM and a crosslinker above the $T_{\mathrm{cp}}$ of both PiPrOx and PNIPAM. Subsequent lowering of the temperature below the $T_{\mathrm{cp}}$ of both polymers allowed extraction of the non-crosslinked PiPrOx core by diffusion through the cross-linked PNIPAM layer leading to hollow thermoresponsive PNIPAM capsules.

A last example where the thermoresponsive behavior of a poly(2-oxazoline) homopolymer was exploited to control assembly processes was reported by Hoogenboom and De Geest et al. for layer-by-layer (LBL) assembly of PnPrOx and tannic acid. ${ }^{96}$ It was demonstrated that LBL assembly of alternating layers of PnPrOx and tannic acid led to much faster growth of the multilayer film thickness when performed above the $T_{\mathrm{cp}}$ of PnPrOx due to adsorption of mesoglobules rather than individual PnPrOx chains as is the case below the $T_{\mathrm{cp}}$.

Since the LCST phase transition of poly(2-oxazoline)s is accompanied by a transition from a hydrophilic to a hydrophobic polymer, this feature can be utilized to obtain temperature control over adsorption and desorption processes. Claesson et al. demonstrated that the adsorption of a block copolymer of PiPrOx as themoresponsive block and poly (3-acrylamidopropyltrimethylammonium chloride) as charged block to adsorb onto a negatively charged silica substrate is indeed temperature dependent. ${ }^{97}$ Upon increasing the temperature, the PiPrOx is partially dehydrated and becomes more hydrophobic which favors the adsorption process leading to an increase in adsorbed mass. This process was found to be reversible and decreasing the temperature led to partial desorption of the block copolymer. The design of such a adsorption-desorption system can also be reversed by attaching the thermoresponsive polymer to a substrate. Dworak and coworkers demonstrated that a PiPrOx or PEtOx-PNonOx thermoresponsive polymer modified glass substrate can be used for temperature controlled cell-culture surfaces. ${ }^{98}$ Cells can be grown and cultured at $37{ }^{\circ} \mathrm{C}$ on the collapsed and dehydrated poly(2-oxazoline) layer. After growth of the cells, it was demonstrated that the cell sheet can easily be removed by simply lowering the temperature below the $T_{\mathrm{cp}}$ of the poly (2-oxazoline). The hydration and swelling of the polymer layer leads to spontaneous detachment of the cell layer. In an improved system, the PiPrOx polymer layer was modified by deposition of PiPrOx crystallites that were formed by annealing of PiPrOx above its $T_{\mathrm{cp}}{ }^{99}$ This modified system enhanced proliferation of the human dermal fibroblast cells while facilitating their detachment from the substrate. A very recent example of temperature controlled adsorption and desorption with thermoresponsive poly(2-oxazoline)s was reported by Maskos and Bertin et al. ${ }^{100}$ PiPrOx coated rhodamine labeled polyorganosiloxane were prepared and their interaction with serum 
proteins was studied. It was demonstrated that the adsorption of serum proteins is significantly enhanced upon heating beyond the $T_{\mathrm{cp}}$ while subsequent cooling below the $T_{\mathrm{cp}}$ led to release of the proteins indicating the reversible nature of this process.

A final application area where thermoresponsive poly (2-oxazoline)s are receiving significant attention is as sensors and molecular logic gates. The most straightforward sensor with a thermoresponsive polymer is as temperature sensor, whereby the polymer phase transition induces clouding of the solution which can be the output signal. Hoogenboom has recently shown that PEtOx-PNonOx copolymers are ideal for this application as the exact phase transition temperature that is 'sensed' can be accurately tuned by addition of different amounts of $\alpha$-cyclodextrins that form host guest complexes with the nonyl side chains, thereby altering the hydrophilic-hydrophobic balance of the copolymer and hence the $T_{\mathrm{cp}}{ }^{101,102}$ Furthermore, it was demonstrated that introducing a large content of hydrophobic PNonOx leads to a widening of the phase transition hysteresis in presence of $\alpha$-cyclodextrins, that is upon heating the clouding of the solution takes place at $50{ }^{\circ} \mathrm{C}$ while upon cooling the solution only turns transparent when cooled below $10^{\circ} \mathrm{C} .{ }^{103}$ This hysteresis originates from the supramolecular host-guest complexation that results in the formation of a meta-stable soluble phase. Once collapsed, reformation of the host-guest complexation only takes place at the original phase transition temperature of the non-complexed polymer. It was shown that this large hysteresis can be exploited as memory function for the molecular thermometer. A solution of the copolymer and $\alpha$-cyclodextrin will remember whether it has been heated beyond $50{ }^{\circ} \mathrm{C}$ or not for more than 1.5 months at room temperature.

A similar sensor concept was developed by Jang, although employing a much more sophisticated fluorescence output signal. ${ }^{104}$ PiPrOx was prepared with a tetraphenylethene end-group that translated the polymer phase transition in a fluorescent output signal. This system acts as a sensor for the polymer concentration as well as the presence of $\gamma$-cyclodextrin. Moreover, the polymer $\gamma$-cyclodextrin host guest complex acts as temperature sensor as collapse of the polymer upon heating releases the $\gamma$-cyclodextrin to the aqueous solution, thereby inducing a change in fluorescence of the tetraphenylethene end-group. Very recently, Jang and coworkers reported PiPrOx end-modified with blue (pyrene), green (boron-dipyrromethene) and red (porphyrin) emissive dyes. ${ }^{105}$ Even though the same PiPrOx polymer was used, the $T_{\mathrm{cp}}$ values were tuned by variation of the polymer chain length and by making star-shaped polymers. As such, the three emissive polymers all had different $T_{\mathrm{cp}} \mathrm{S}$ and each of the individual polymers acts as a temperature sensor. However, by careful optimization of the concentration of the three polymers in one solution it was possible to design systems with different emission color in response to variations in temperature as shown in Fig. 6.

The final two examples describe the use of multiresponsive poly(2-oxazoline)s for molecular logic gate operations. Hoogenboom et al. reported the preparation of poly(2-oxazoline) coated gold nanoparticles that aggregate and change color from red to purple upon increasing the temperature above the $T_{\mathrm{cp}}$ of the polymer coating and in presence of sodium chloride. ${ }^{106}$ It was demonstrated that the system operates as AND logic gate and that only a color change occurs when both triggers are present. Variation of the poly (2-oxazoline) from PiPrOx to PEtOx allowed tuning of the temperature required for the input. A triple responsive poly(2-oxazoline) was developed by Ju and Jang as AND-OR logic gates with the solution being opaque or transparent as output signal. ${ }^{107}$ PiPrOx was prepared having two azobenzene end-groups, whereby the PiPrOx induces thermoresponsivity while photoisomerization of the azobenzene governs host-guest complexation with either $\alpha$-cyclodextrin in the trans-form and with $\beta$-cyclodextrin in the cis-form. The AND-OR logic gate operation is based on photoirradiation for isomerization of the azobenzene, presence of cyclodextrin and the temperature as input signals.
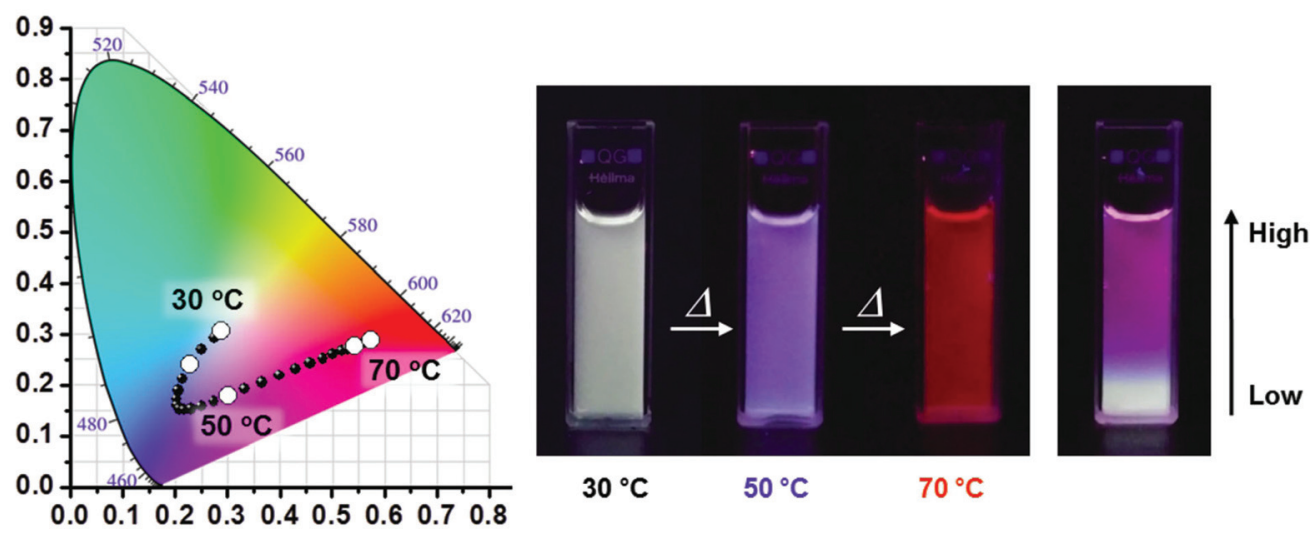

Fig. 6 Temperature-dependent fluorescence emission changes of three-component mixtures of PiPrOx modified with pyrene (blue), borondipyrromethene (green) and porphyrin (red). The right picture show the solution with a temperature gradient from bottom to top. Reprinted with permission from ref. 105. Copyright 2016 WILEY-VCH Verlag GmbH \& Co. KGaA. 


\subsection{Polypeptoids}

Polypeptoids, i.e., poly $(N$-alkyl glycine $) \mathrm{s},{ }^{8}$ in aqueous solution can exhibit lower critical solution (LCST) behavior, which they share with other tertiary amides like poly(2-oxazoline)s (see previous section) and also poly(meth)acrylamides. ${ }^{2,3}$

Peptoid homopolymers with methyl $\left(\mathrm{C}_{1}\right.$, sarcosine $)$ and ethyl $\left(\mathrm{C}_{2}\right)$ side chains are readily soluble in water while all other polypeptoids with longer alkyl side chains $\left(\mathrm{C}_{3}\right.$ and longer) were found to be insoluble. ${ }^{108}$ Afterwards, it has been demonstrated that amorphous samples of polypeptoids with $\mathrm{C}_{3}$ side chains, i.e., n-propyl, allyl, and i-propyl (Fig. 7), can be dissolved in water at 20-40 $\mathrm{g} \mathrm{L}^{-1}$ and show LCST behavior; poly( $N$-propargylglycine), however, remains insoluble in water. ${ }^{109,110}$ The cloud point temperatures $\left(T_{\mathrm{cp}}\right)$ were found to increase in the order $n$-propyl $\left(15-25{ }^{\circ} \mathrm{C}\right)<$ allyl $\left(27-54{ }^{\circ} \mathrm{C}\right)$ $<$ i-propyl (47-58 ${ }^{\circ} \mathrm{C}$ ), depending on the chain length and polymer concentration (classical Flory-Huggins type 1 behavior). The phase transitions were reversible only for shorter time scales of a few hours. Long-term annealing of dilute aqueous solutions of poly $(N-n$-propylglycine $)$ and poly $(N$-allylglycine) resulted in the formation of crystalline precipitates (melting at $188-198{ }^{\circ} \mathrm{C}$ and $157-165{ }^{\circ} \mathrm{C}$, respectively) with complex morphologies ( $c f$. crystallization of PEtOx or PiPrOx in hot water, see above). ${ }^{109}$

It is worth to mention that thermoresponsive polypeptoid homopolymer fiber mats could be prepared by electrospinning of blends of semicrystalline poly( $N$ - $n$-propylglycine) and high molar mass poly(ethylene oxide) (PEO). ${ }^{111}$ Annealing of the electrospun fibers at about $100{ }^{\circ} \mathrm{C}$ and subsequent washing with water selectively removed the amorphous PEO fraction to give stable crystalline poly( $N$ - $n$-propylglycine $)$ fibers.
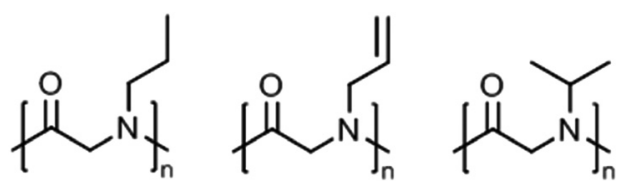

Fig. 7 Thermoresponsive polypeptoid homopolymers.
Thermo-induced aggregation and crystallization (see above) was observed for poly( $N$ - $n$-propylglycine)-polysarcosine diblock copolypeptoids in water (double hydrophilic at $T<T_{\mathrm{cp}}$ and amphiphilic at $\left.T>T_{\mathrm{cp}}\right) .{ }^{112}$ Interestingly, the morphology of initially spherical aggregates at $T>T_{\mathrm{cp}}$ was not retained during crystallization of the hydrophobic poly( $N$ - $n$-propylglycine) core, resulting in the formation of larger complex assemblies (100-500 nm in size) with flower-like, ellipsoidal, or irregular shapes (Fig. 8). Evidently, the crystallization of the hydrophobic core is not applicable for the stabilization of aggregates against dilution, as for instance desirable in drug delivery applications. Also, the incorporation of hydrophobic molecules or drugs into the crystallized compartment might be difficult.

The $T_{\mathrm{cp}}$ values could be adjusted for statistical copolymers with hydrophilic units, usually sarcosine or $N$-ethylglycine, and hydrophobic units, usually butyl or higher alkyl substituted glycines, at various ratios. Examples include poly[sarcosineran-( $N$-butylglycine $)]$ with tunable $T_{\mathrm{cp}}$ values in the range of 27-71 ${ }^{\circ} \mathrm{C}$ (at $0.3 \mathrm{wt} \%$ in water; sarcosine content increasing from 42 to $73 \mathrm{~mol} \%)^{113,114}$ and poly[( $N$-ethylglycine)-stat( $N$-butylglycine)] $20-60{ }^{\circ} \mathrm{C}$ (at $0.1 \mathrm{wt} \%$ in water). ${ }^{115}$ For the latter case, a distinct impact of the architecture, linear vs. cyclic, on $T_{\mathrm{cp}}$ could be recognized. The phase transition of the cyclic copolypeptoids was shifted to lower temperature, by five degrees or less, as compared to the linear analogue with the same composition, which was explained in terms of lower entropic loss. Also, the $T_{\mathrm{cp}}$ was found to decrease upon the addition of sodium salts, the degree of depression being in line with the Hofmeister series, i.e., sulphate $>$ chloride > iodide. Such a salting-in/out effect was also observed for poly[sarcosine-ran-( $N$-butylglycine $)]{ }^{114}$

Interestingly, when comparing linear norbornyl-poly $[(\mathrm{N}$ ethylglycine)-ran-( $N$-butylglycine)] and polynorbornene-graftpoly[( $N$-ethylglycine)-ran-( $N$-butylglycine $)]$ bottlebrushes (prepared by ring-opening metathesis polymerization, ROMP), the polymer architecture seemed to have no impact on the $T_{\mathrm{cp}}{ }^{116}$ However, the phase behavior was strongly dependent on the thermal history of the samples and the presence of inorganic salts.
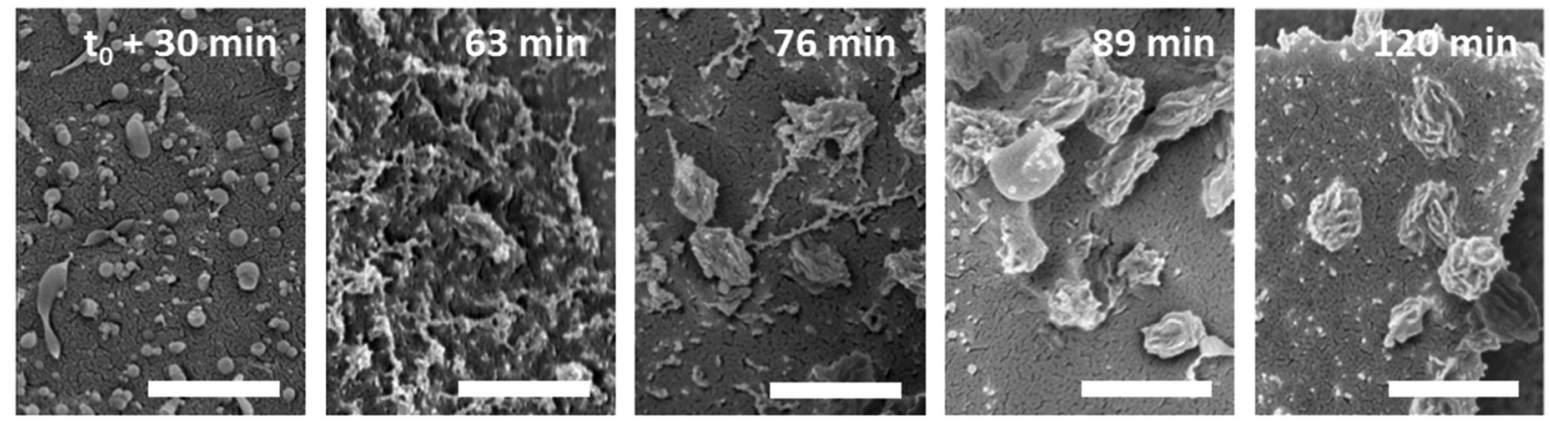

Fig. 8 Time-dependant evolution of aggregate structures, as visualized by cryogenic scanning electron microscopy (scale bar = $500 \mathrm{~nm}$ ), in $1 \mathrm{wt} \%$ aqueous solutions of poly $(N-n \text {-propylglycine })_{70}$-block-polysarcosine 23 at $48{ }^{\circ} \mathrm{C}\left(T>T_{\mathrm{cp}}\right)$. Reprinted (modified) with permission from ref. 112 . Copyright 2016 American Chemical Society. 


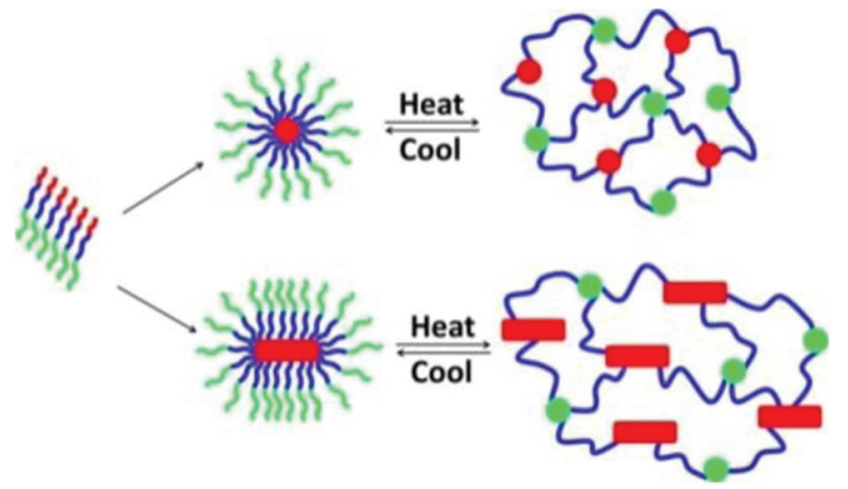

Fig. 9 Schematic representation of the gelation mechanism of aqueous solutions of $A B C$ triblock copolypeptoid; red $=\operatorname{poly}(N$-allylglycine $)$, green $=$ polysarcosine, blue $=$ poly $(N-n$-decylglycine $)$. Reprinted with permission from ref. 117. Copyright 2016 American Chemical Society.

ABC block copolypeptoids, i.e., poly( $N$-allylglycine)-blockpolysarcosine-block-poly( $N$ - $n$-decylglycine), were found to undergo sol-to-gel transitions with increasing temperature in aqueous solutions at 2.5-10 wt\% (Fig. 9). ${ }^{117}$ The gelation temperature $\left(T_{\text {gel }}\right)$ and mechanical properties (storage modulus, $G^{\prime}$, and Young's modulus, E) of the hydrogel could be tuned in the range of $T_{\text {gel }}=26-60{ }^{\circ} \mathrm{C}, G^{\prime}=0.2-780 \mathrm{~Pa}$, and $E=0.5-2346 \mathrm{~Pa}$, by varying the copolypeptoid composition and polymer concentration. The hydrogels are injectable through a 24 gauge $(0.635 \mathrm{~mm})$ syringe, maintain their shape upon contact with surfaces, and exhibit minimal cytotoxicity.

\subsection{Polypeptides}

Synthetic polypeptides ${ }^{118,119}$ based on naturally occuring amino acids do not exhibit thermoresponsive solution behavior, except elastin-mimetic peptide sequences or elastinlike polypeptides (ELPs) ${ }^{120}$ made by genetic engineering techniques (not considered here). Thermoresponsive polypeptide materials have been obtained by grafting hydrophilic side chains, usually tertiary amine, oligo(ethylene glycol) or poly[oligo(ethylene glycol) methacrylate], onto a hydrophobic poly $(\gamma$-substituted L-glutamate) or side chain modified poly(L-cysteine) and poly(L-lysine).

2.3.1 Polyglutamate-based polymers. Dilute solutions of linear poly(L-glutamate)s with diethylene glycol and/or tertiary amine side chains (Fig. 10a) exhibited $T_{\mathrm{cp}}$ values in the range of $25-75{ }^{\circ} \mathrm{C}$ depending on chain length and composition as well as on solution $\mathrm{pH}$ (for amine containing polypeptides). ${ }^{121}$ The longer the polypeptide backbone and higher the amount of diethylene glycol, the lower was the $T_{\mathrm{cp}}$ in deionized water. For diethylene glycol/amine containing polypeptides, the $T_{\mathrm{cp}}$ was found to increase for polypeptides with increasing amine content and decreasing solution $\mathrm{pH}$ (5.6-6.6; $100 \mathrm{mM} \mathrm{NaCl}$, $75 \mathrm{mM}$ phosphate buffer). Furthermore, it was revealed that the helictity of diethylene glycol/amine-substituted polypeptides decreased with increasing temperature $\left(25-40{ }^{\circ} \mathrm{C}\right)$. Similar results were reported for a slightly different poly(L-glutamate) derivative, i.e., poly( $\gamma$-propyl-t-glutamate)-graft-(oligoethylene glycol). ${ }^{122}$

Aqueous solutions of diethylene glycol/galactose functionalized poly(L-glutamate)s (Fig. 10b) exhibited $T_{\mathrm{cp}}$ values in the range of $15-80^{\circ} \mathrm{C}$, the $T_{\mathrm{cp}}$ values increasing linearly with galactose content $(0-24 \%) .{ }^{123}$ These glycopolypeptides were designed for use in temperature controlled biological response, here, the specific recognition of lectins via selective carbohydrate-protein interactions. Lectin binding appeared to occur only at a temperature below $T_{\mathrm{cp}}$ and was suppressed at above $T_{\mathrm{cp}}$.

A systematic study on the $\mathrm{pH}^{-}$and thermo-responsiveness of tertiary amine functionalized poly(L-glutamate)s (Fig. 11) revealed that the $T_{\mathrm{cp}}$ depended delicately on the alkyl spacer (between triazole and amine) and the $N$-substituted groups. ${ }^{124}$ Polypeptides with moderate $N$-substituted amine group (e.g., diethylamine, pyrolidine, and piperidine) or branched spacer displayed more likely an LCST-type phase transition $\left(T_{\mathrm{cp}} \sim 15-50{ }^{\circ} \mathrm{C}\right)$, tuned by $\mathrm{pH}$ variation, than polypeptides with (lower substituted) amine, methylamine, dimethylamine, and morpholine groups or (higher substituted) diisopropylamine and hexamethylene groups. Interestingly, the diisopropylamine substituted poly(L-glutamate) exhibited different behaviors in acidified water (no phase transition) ${ }^{124}$ and in aqueous phosphate buffer $\left(T_{\mathrm{cp}}=38-66{ }^{\circ} \mathrm{C}\right.$ at $\left.\mathrm{pH} 5.0-6.2\right),{ }^{121}$ which might be attributed to a salting out effect.

Tang et al. introduced very special types of thermoresponsive helical poly( $\gamma$-benzyl-L-glutamate)s bearing alkyl/ oligoethylene glycol triazolium side chains (Fig. 12a) ${ }^{125}$ or alkyl imidazolium side chains (Fig. 12b), ${ }^{126}$ which can be regarded as poly(ionic liquid)s. ${ }^{127,128}$ The first polypeptide

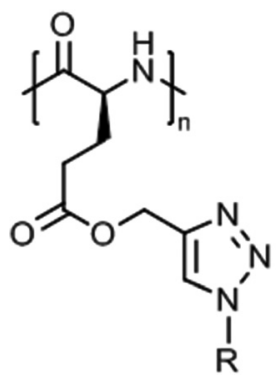

(a)

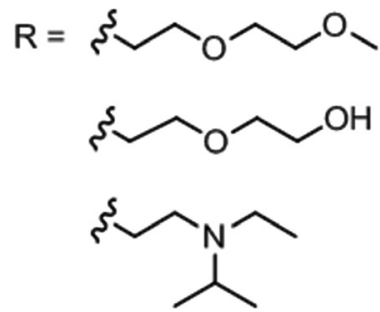

(b)

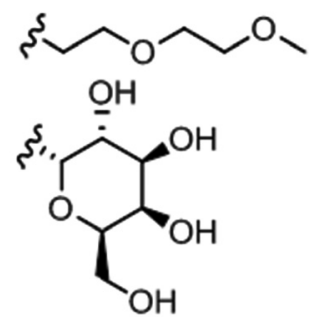

Fig. 10 Themoresponsive poly(L-glutamate)s with (a) diethylene glycol/tertiary amine side chains and (b) diethylene glycol/galactose side chains. 
<smiles>[R]n1cc(COC(=O)CC[C@H](NC(C)(C)C)C(=O)C(C)(C)C)nn1</smiles><smiles>CCN(CC)CCSCCCCCN1CCCC1</smiles><smiles>CNCC[Te]</smiles><smiles>CCCCCN(C)C</smiles><smiles>CN(C)CC[As]</smiles><smiles>CC(C)CN(C)C</smiles><smiles>CN(C)CCCS</smiles><smiles>CC(CS)CN(C)C</smiles>

Fig. 11 Thermo- and pH-responsive poly(L-glutamate)s with amine side chains.

(a)

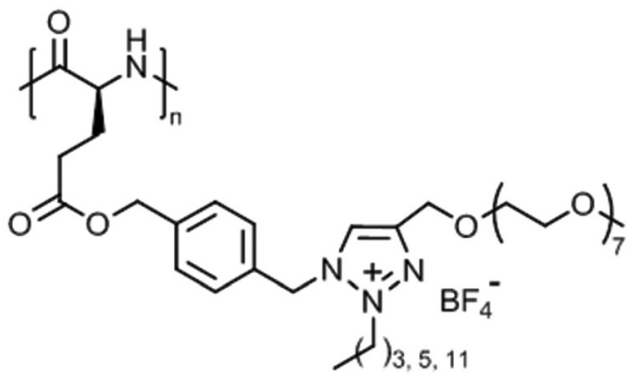

(b)

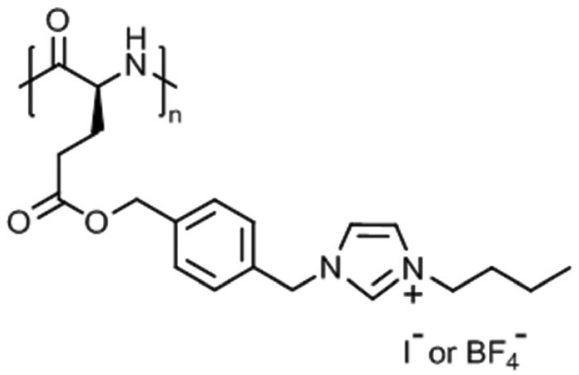

Fig. 12 Thermoresponsive poly( $\gamma$-benzyl-L-glutamate)s with (a) alkyl/oligoethylene glycol triazolium and (b) $n$-butyl imidazolium side chains.<smiles>CC(C)(C)N[C@@H](CCC(=O)OCc1ccccc1)C(=O)C(C)(C)N[C@@H](CCC(=O)OCCCn1cc(COCCOC(C)(C)C)nn1)C(=O)C(C)(C)C</smiles>

Fig. 13 Thermoresponsive copoly(L-glutamate) with benzyl and triethylene glycol side chains.

exhibited LCST behavior in deionized water and the $T_{\mathrm{cp}}$ could be varied in the range of $40-75{ }^{\circ} \mathrm{C}$, depending on the alkyl/oligoethylene glycol substitution (alkyl = butyl, hexyl, dodecyl) and polymer concentration $(0.1-0.6 \mathrm{wt} \%) .{ }^{125}$ The $T_{\mathrm{cp}}$ 's were also affected considerably by the presence of salt $\left(\mathrm{NaBF}_{4}\right)$, i.e., $\Delta T=$ $-5{ }^{\circ} \mathrm{C}$ to $-25{ }^{\circ} \mathrm{C}$, due to salting out effect. The most pronounced effect, however, was found for the permanently charged polypeptide with butyl/oligoethylene glycol side chains at $0.6 \mathrm{wt} \% \mathrm{NaBF}_{4}$.

The second polypeptide with $n$-butyl imidazolium side chains, however, showed UCST behavior in deionized water. ${ }^{126}$
Depending on the counter ion, $\mathrm{I}^{-}$or $\mathrm{BF}_{4}^{-}$, the transition or clearing temperature was $35^{\circ} \mathrm{C}$ or $69^{\circ} \mathrm{C}$, respectively, at $0.1 \mathrm{wt} \%$; no phase transition was observed for polypeptides with alkyl $=$ methyl $/ \mathrm{Cl}^{-}, \mathrm{I}^{-}, \mathrm{BF}_{4}{ }^{-}$and $n$-butyl $/ \mathrm{Cl}^{-}$. The transition temperature was unaffected by the polymer chain length but was significantly affected by salts, and it increased in the presence of $\mathrm{NaI}$ and $\mathrm{NaBF}_{4}$ and decreased in the presence of $\mathrm{NaCl}$ ( $c f$. Hofmeister series). This effect was ascribed to electrostatic interactions and anionic exchange reactions.

Water-soluble random copoly(L-glutamate)s with benzyl and triethylene glycol pendants (Fig. 13) were found to exhibit 
(a)

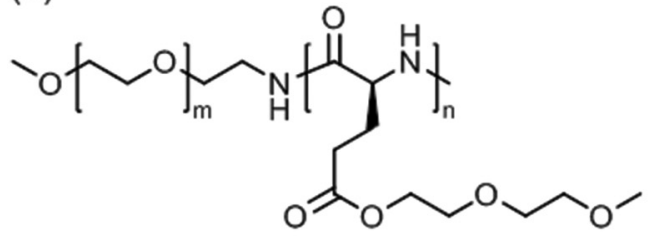

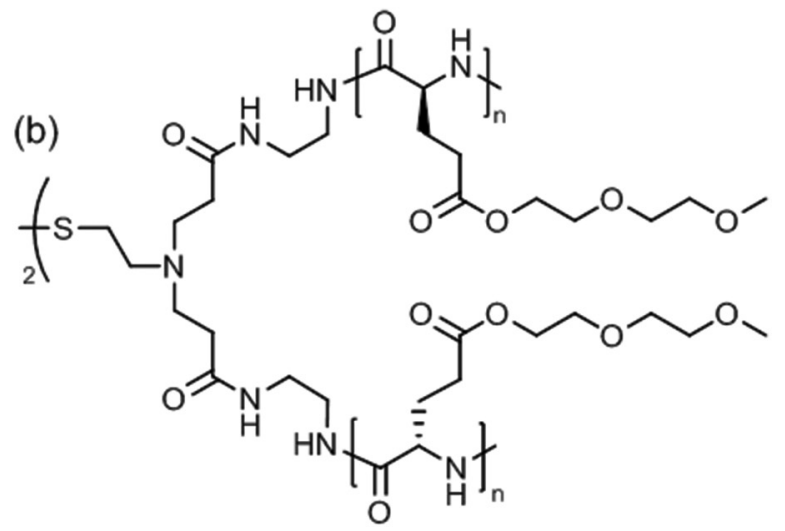

Fig. 14 Thermoresponsive poly[ $\gamma$-(methoxy diethylene glycol)-L-glutamate]-based (a) block copolymer and (b) 4-arm star polymer.

thermoresponsive properties. ${ }^{129}$ Depending on the composition, i.e., ratio of hydrophobic benzyl groups $v s$. hydrophilic triethylene glycol groups, the $T_{\mathrm{cp}}$ could be tuned between $22{ }^{\circ} \mathrm{C}$ (57\% hydrophilic units) and $53{ }^{\circ} \mathrm{C}$ (90\% hydrophilic units) (at $0.2 \mathrm{wt} \%$ in water). Furthermore, the helicity of copolypeptide chains increased from $65 \%$ to $90 \%$ with increasing triethylene glycol content.

Linear poly(ethylene glycol $)_{45}$-block-poly[ $\gamma$-(methoxy diethylene glycol)-L-glutamate $]_{43}$ (Fig. 14a) was soluble in water (or $100 \mathrm{mM} \mathrm{NaCl}$ solution) at room temperature but formed wormlike micelles at a temperature above $T_{\mathrm{cp}}=53{ }^{\circ} \mathrm{C} \cdot{ }^{130}$ Aggregation occurred due to the temperature-induced dehydration of the polypeptide block without affecting its $\alpha$-helical conformation. Extension of the thermal annealing time $\left(12\right.$ hours at $\left.80^{\circ} \mathrm{C}\right)$ drove the secondary structure transformation of the polypeptide block from $\alpha$-helix to $\beta$-sheet, which accounted for a transition from wormlike micelles into nanoribbons measuring about $70 \mathrm{~nm}$ in width and several micrometers in length.

Star-shaped poly[ $\gamma$-(methoxy diethylene glycol)-L-glutamate] with a disulfide-containing core (apparent molar mass, $M_{\mathrm{n}}=$ 15.5 or $33.8 \mathrm{kDa}$ ) (Fig. 14b) exhibited dual thermo- and redoxresponsiveness. ${ }^{131}$ Addition of dithiothreitol to the aggregates in water reduced the disulfide bonds, cutting the 4 -arm star polypeptide into 2-arm star (linear) fragments, which however caused a reduction of the size of aggregates from about $330 \mathrm{~nm}$ to $180 \mathrm{~nm}$. The aggregate size gradually decreases upon heating $\left(20-50{ }^{\circ} \mathrm{C}\right)$ due to the collapse of the polypeptide side chains; the process could be reversed by cooling. Interestingly, 3-4 wt $\%$ aggregate solutions formed a hydrogel at room temperature, which could be dissolved upon heating to above $T_{\mathrm{cp}} \sim 40^{\circ} \mathrm{C}$.

The graft copolymer (or molecular bottlebrush) poly(L-glutamate)-graft-poly[2-(2-methoxyethoxy)ethyl methacrylate] (molar mass, $M_{\mathrm{n}}=221 \mathrm{kDa}$ ) (Fig. 15a) exhibited thermoresponsive LCST behavior in aqueous solution. ${ }^{132}$ The phase transition was rather broad in pure water $\left(T_{\mathrm{cp}} \sim 27{ }^{\circ} \mathrm{C}\right)$ but sharp in saline solution $\left(T_{\mathrm{cp}}=22-23{ }^{\circ} \mathrm{C}, 0.1-0.9 \mathrm{wt} \% \mathrm{NaCl}\right)$. It was stated, based on circular dichroism spectroscopic measurements, that the helicity of polypeptide chains (DP $\sim 45)$ was almost $100 \%$ at $25{ }^{\circ} \mathrm{C}$ and also at $60{ }^{\circ} \mathrm{C}$. Aggregates (assumed to be spheres with helical polypeptide core and thermoresponsive polymethacrylate shell) were formed in water, measuring $150 \mathrm{~nm}$ in diameter at $25^{\circ} \mathrm{C}$ and $60 \mathrm{~nm}$ at $60^{\circ} \mathrm{C}$.

Also the "hairy-rod" polypeptides consisting of a poly(L-glutamate $)_{40}$ backbone and poly[(methoxy diethylene glycol methacrylate)-ran-(methoxy triethylene glycol methacrylate)] side chains (grafting ratio $\sim 90 \%$; molar mass, $M_{\mathrm{n}}=$ 195-227 kDa) (Fig. 15b) displayed thermoresponsive properties. ${ }^{133}$ The $T_{\mathrm{cp}}$ values, measured at $2 \mathrm{wt} \%$ in physiological<smiles>CNC(CCC(=O)OCCCC(C)(C)C(=O)OCCOCCOC)C(C)=O</smiles>

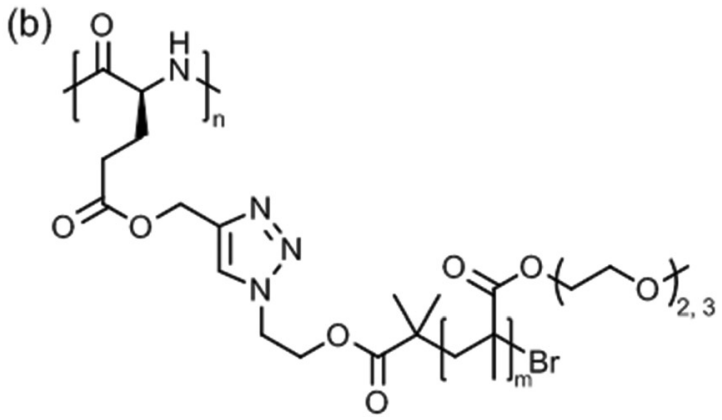

Fig. 15 Thermoresponsive "hairy-rod" graft copolymers with poly(L-glutamate) backbone and poly[methoxy oligo(ethylene glycol) methacrylate] side chains, prepared by (a) grafting from and (b) grafting onto. 

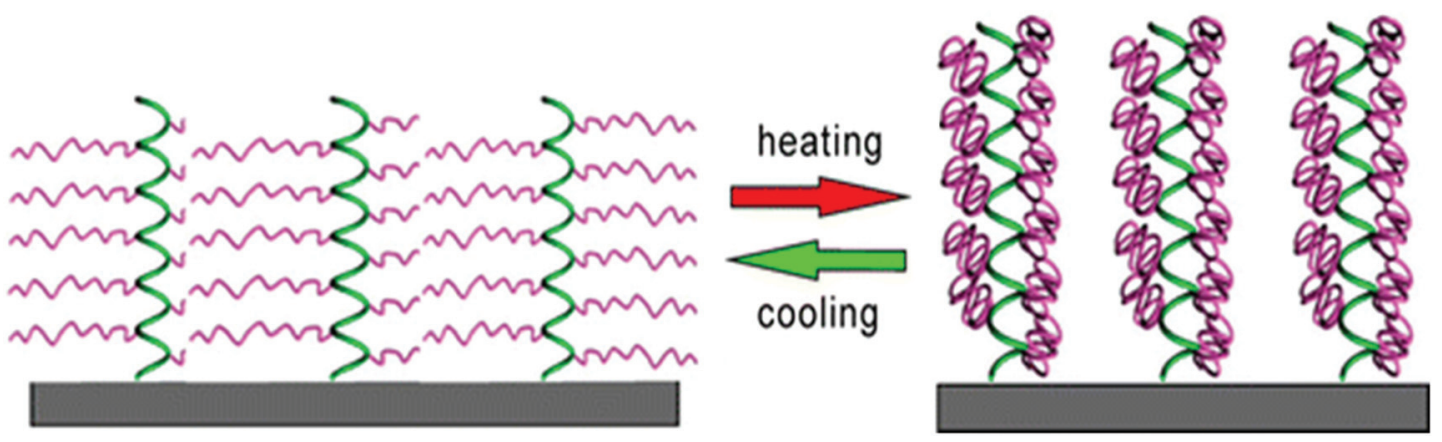

Fig. 16 Thermo-induced hydration/dehydration of polypeptide brushes; green $=$ helical poly(L-glutamate) backbone, purple = thermoresponsive oligoethylene glycol side chains. Reprinted with permission from ref. 134. Copyright 2015 American Chemical Society.

(a)<smiles>[R]S[As]CC(NCC)C(C)=O</smiles>

(b)<smiles>[R]C=NOCC(=O)NCCCC[C@H](NC(C)C)C(C)(C)C(C)=O</smiles><smiles>[Y]=[W]=[W]</smiles><smiles>CCC(C)C(=O)OCCOC</smiles><smiles>CCC(O)COCCOC</smiles><smiles>CCC(O)COCCOC(C)=O</smiles><smiles>CCOCCOCC(C)OCCOCC(C)C(O)CC(C)OCCOCC</smiles><smiles>CCC(O)C(C)OCCOC</smiles><smiles>[R]=[W]c1cc(OCCOCCOCCOCC)c(OCCOCCOCCOCC)c(OCCOCCOCCOCC)c1</smiles><smiles>COCCO</smiles><smiles>CCOc1cc(OC)cc(OCC)c1</smiles> 
saline solution $(0.9 \mathrm{wt} \% \mathrm{NaCl})$, were found to increase from $20{ }^{\circ} \mathrm{C}$ to $41{ }^{\circ} \mathrm{C}$ with increasing hydrophilicity of the side chains, i.e., increasing amount of methoxy triethylene glycol methacrylate. In the same line, the hydrodynamic size of the aggregates formed in water increased from $170 \mathrm{~nm}$ to $310 \mathrm{~nm}$. All polypeptide copolymers adopted 100\% $\alpha$-helical conformation, except the most hydrophilic one bearing poly(methoxy triethylene glycol methacrylate) side chains, $72 \%$.

Klok et al. synthesized surface-tethered helical poly $\left[\gamma\right.$-(oligoethylene glycol)-L-glutamate) brushes. ${ }^{134}$ The polypeptide chains did not undergo any changes in the secondary structure between $10{ }^{\circ} \mathrm{C}$ and $70{ }^{\circ} \mathrm{C}$, but revealed a significant dehydration upon heating from $10^{\circ} \mathrm{C}$ to $40{ }^{\circ} \mathrm{C}$. Interestingly, the film thickness remained unchanged due to the shapepersistant nature of the polypeptide brushes (Fig. 16).

2.3.2 Other polypeptide-based polymers. Poly(L-cysteine) modified with monomethoxy oligoethylene glycol (meth)acrylate (Fig. 17a, $x=0$ ) were found to exhibit thermoresponsive behavior when the number of ethylene glycol units was between 3 and 5 ; the $T_{\mathrm{cp}}$ values were in the range of $50-70{ }^{\circ} \mathrm{C}$ at $0.2 \mathrm{wt} \%$ in water. ${ }^{135}$ Deming et al. achieved a more predictable and wider tuning of $T_{\mathrm{cp}}$, i.e., $T_{\mathrm{cp}}=30-80{ }^{\circ} \mathrm{C}$, with oligoethylene glycol-modified poly(L-homocysteine)s (Fig. 17a, $x=1) .{ }^{136}$ The $T_{\mathrm{cp}}$ values were also found to be sensitive to the presence of Hofmeister salts $\left(\Delta T= \pm 20^{\circ} \mathrm{C}\right)$. Oxidation of the thioether linker to sulfoxide or sulfone led to an increase of the hydrophilicity of the polypeptide and thus increase of the $T_{\mathrm{cp}}$ to above the boiling point of water.

Poly(L-lysine)s bearing triethylene glycol dendrons of generation 1 and 2 (Fig. 17b) exhibited LCST behavior in $\mathrm{pH} 7$ buffered aqueous solutions. ${ }^{137}$ At $0.1 \mathrm{wt} \%$, the cloud point temperatures were in the range of $30-37^{\circ} \mathrm{C}$ depending on the polypeptide chain length and dendron generation.

\section{Summary}

Poly(2-oxazoline)s, polypeptoids, and polypeptides are interesting materials especially for use in biomedical applications, which not least is due to their good (bio-) compatibility and degradability. Recent efforts were focussed to implement external stimuli-responsiveness, for instance to temperature, $\mathrm{pH}$, etc., to these polymers for the generation of advanced smart materials.

Thermoresponsive poly(2-oxazoline)s are known for almost three decades while thermoresponsive polypeptoids and polypeptides have just emerged during the last five years (however, thermoresponsive elastin-like polypeptides and $\mathrm{pH}$-responsive polypeptides are known for much longer). Accordingly, the research in thermoresponsive materials based on poly(2-oxazoline)s is far more established and yet more applications have been developed, for instance as biomedical devices, sensors, or molecular logic gates, as compared to polypeptoids and polypeptides. Applications of thermoresponsive polypeptoids and polypeptides are still scarce, which with the rapid research developments should change in the very near future.
Key parameter for the control of the thermoresponsive properties of a polymer, no matter if it is a poly(2-oxazoline), polypeptoid, polypeptide, or any other kind of material, is the hydrophilic-hydrophobic balance. This balance can be tuned by the proper choice of side chains or by the copolymerization of hydrophilic and hydrophobic monomers. Also the blending of homopolymers might be a suitable approach to tune the thermoresponsive behavior.

Yet a plethora of thermoresponsive polyamides have been prepared based of this concept of hydrophilic-hydrophobic balance (or by trial and error), though the self-assembly behavior, structure formation, and applications need to be further explored.

\section{Acknowledgements}

Katharina Zesch is thanked for proofreading of the manuscript.

\section{References}

1 M. A. Cohen Stuart, W. T. S. Huck, J. Genzer, M. Muller, C. Ober, M. Stamm, G. B. Sukhorukov, I. Szleifer, V. V. Tsukruk, M. Urban, F. Winnik, S. Zauscher, I. Luzinov and S. Minko, Nat. Mater., 2010, 9, 101-113.

2 I. Dimitrov, B. Trzebicka, A. H. E. Müller, A. Dworak and C. B. Tsvetanov, Prog. Polym. Sci., 2007, 32, 1275-1343.

3 V. Aseyev, H. Tenhu and F. Winnik, Adv. Polym. Sci., 2011, 242, 29-89.

4 C. Weber, R. Hoogenboom and U. S. Schubert, Prog. Polym. Sci., 2012, 37, 686-714.

5 J. Seuring and S. Agarwal, Macromol. Rapid Commun., 2012, 33, 1898-1920.

6 G. Vancoillie, D. Frank and R. Hoogenboom, Prog. Polym. Sci., 2014, 39, 1074-1095.

7 Q. Zhang and R. Hoogenboom, Prog. Polym. Sci., 2015, 48, 122-142.

8 N. Gangloff, J. Ulbricht, T. Lorson, H. Schlaad and R. Luxenhofer, Chem. Rev., 2016, 116, 1753-1802.

9 H. Schlaad, C. Diehl, A. Gress, M. Meyer, A. L. Demirel, Y. Nur and A. Bertin, Macromol. Rapid Commun., 2010, 31, 511-525.

10 M. A. Ward and T. K. Georgiou, Polymers, 2011, 3, 12151242.

11 C. Pietsch, U. S. Schubert and R. Hoogenboom, Chem. Commun., 2011, 47, 8750-8765.

12 M. R. Islam, Z. Z. Lu, X. Li, A. K. Sarker, L. Hu, P. Choi, X. Li, N. Hakobyan and M. J. Serpe, Anal. Chim. Acta, 2013, 789, 17-32.

13 J. K. Chen and C. J. Chang, Materials, 2014, 7, 805-875.

14 A. Gandhi, A. Paul, S. O. Sen and K. K. Sen, Asian J. Pharm. Sci., 2015, 10, 99-107.

15 H. R. Kricheldorf, Angew. Chem., Int. Ed., 2006, 45, 57525784 . 
16 K. Aoi and M. Okada, Prog. Polym. Sci., 1996, 21, 151-208.

17 B. Verbraeken, K. Lava and R. Hoogenboom, in Encyclopedia of Polymer Science and Technology, John Wiley \& Sons, Inc., 2014.

18 D. A. Tomalia and D. P. Sheetz, J. Polym. Sci., Part A: Polym. Chem., 1966, 4, 2253-2265.

19 W. Seeliger, E. Aufderhaar, W. Diepers, R. Feinauer, R. Nehring, W. Thier and H. Hellmann, Angew. Chem., Int. Ed., 1966, 5, 875-888.

20 T. Kagiya, S. Narisawa, T. Maeda and K. Fukui, J. Polym. Sci., Part B: Polym. Lett., 1966, 4, 441-445.

21 T. G. Bassiri, A. Levy and M. Litt, J. Polym. Sci., Part B: Polym. Lett., 1967, 5, 871-879.

22 R. Hoogenboom, M. W. M. Fijten, H. M. L. Thijs, B. M. van Lankvelt and U. S. Schubert, Des. Monomers Polym., 2005, 8, 659-671.

23 E. Rossegger, V. Schenk and F. Wiesbrock, Polymers, 2013, 5, 956-1011.

24 B. Guillerm, S. Monge, V. Lapinte and J.-J. Robin, Macromol. Rapid Commun., 2012, 33, 1600-1612.

25 K. Lava, B. Verbraeken and R. Hoogenboom, Eur. Polym. J., 2015, 65, 98-111.

26 P. Y. Lin, C. Clash, E. M. Pearce, T. K. Kwei and M. A. Aponte, J. Polym. Sci., Part B: Polym. Phys., 1988, 26, 603-619.

27 D. Christova, R. Velichkova, W. Loos, E. J. Goethals and F. Du Prez, Polymer, 2003, 44, 2255-2261.

28 R. Hoogenboom, H. M. L. Thijs, M. J. H. C. Jochems, B. M. van Lankvelt, M. W. M. Fijten and U. S. Schubert, Chem. Commun., 2008, 5758-5760.

29 A. Kowalczuk, J. Kronek, K. Bosowska, B. Trzebicka and A. Dworak, Polym. Int., 2011, 60, 1001-1009.

30 M. A. Cortez, W. T. Godbey, Y. Fang, M. E. Payne, B. J. Cafferty, K. A. Kosakowska and S. M. Grayson, J. Am. Chem. Soc., 2015, 137, 6541-6549.

31 J. Xu, J. Ye and S. Liu, Macromolecules, 2007, 40, 91039110.

32 N. Ten Brummelhuis and H. Schlaad, Polym. Chem., 2011, 2, 1180-1184.

33 R. Chapman, P. J. M. Bouten, R. Hoogenboom, K. A. Jolliffe and S. Perrier, Chem. Commun., 2013, 49, 6522-6524.

34 C. Weber, S. Rogers, A. Vollrath, S. Hoeppener, T. Rudolph, N. Fritz, R. Hoogenboom and U. S. Schubert, J. Polym. Sci., Part A: Polym. Chem., 2013, 51, 139-148.

35 M. M. Bloksma, D. J. Bakker, C. Weber, R. Hoogenboom and U. S. Schubert, Macromol. Rapid Commun., 2010, 31, 724-728.

36 P. T. Güner and A. L. Demirel, J. Phys. Chem. B, 2012, 116, 14510-14514.

37 N. ten Brummelhuis, C. Secker and H. Schlaad, Macromol. Rapid Commun., 2012, 33, 1690-1694.

38 J.-F. Lutz, Ö. Akdemir and A. Hoth, J. Am. Chem. Soc., 2006, 128, 13046-13047.

39 P. T. Güner, A. Miko, F. F. Schweinberger and A. L. Demirel, Polym. Chem., 2012, 3, 322-324.

40 H. Uyama and S. Kobayashi, Chem. Lett., 1992, 21, 16431646.
41 J. Zhao, R. Hoogenboom, G. Van Assche and B. Van Mele, Macromolecules, 2010, 43, 6853-6860.

42 C. Diab, Y. Akiyama, K. Kataoka and F. M. Winnik, Macromolecules, 2004, 37, 2556-2562.

43 J.-S. Park, Y. Akiyama, F. M. Winnik and K. Kataoka, Macromolecules, 2004, 37, 6786-6792.

44 S. Salzinger, S. Huber, S. Jaksch, P. Busch, R. Jordan and C. M. Papadakis, Colloid Polym. Sci., 2012, 290, 385-400.

45 A. I. Amirova, M. M. Dudkina, A. V. Tenkovtsev and A. P. Filippov, Colloid Polym. Sci., 2015, 293, 239-248.

46 N. Zhang, R. Luxenhofer and R. Jordan, Macromol. Chem. Phys., 2012, 213, 973-981.

47 R. Obeid, F. Tanaka and F. M. Winnik, Macromolecules, 2009, 42, 5818-5828.

48 S. Huber, N. Hutter and R. Jordan, Colloid Polym. Sci., 2008, 286, 1653-1661.

49 M. Meyer, M. Antonietti and H. Schlaad, Soft Matter, 2007, 3, 430-431.

50 A. L. Demirel, M. Meyer and H. Schlaad, Angew. Chem., Int. Ed., 2007, 46, 8622-8624.

51 C. Diehl, P. Cernoch, I. Zenke, H. Runge, R. Pitschke, J. Hartmann, B. Tiersch and H. Schlaad, Soft Matter, 2010, 6, 3784-3788.

52 Y. Katsumoto, A. Tsuchiizu, X. P. Qiu and F. M. Winnik, Macromolecules, 2012, 45, 3531-3541.

53 T. Li, H. Tang and P. Wu, Langmuir, 2015, 31, 6870-6878.

54 J.-S. Park and K. Kataoka, Macromolecules, 2007, 40, 35993609.

55 M. M. Bloksma, C. Weber, I. Y. Perevyazko, A. Kuse, A. Baumgärtel, A. Vollrath, R. Hoogenboom and U. S. Schubert, Macromolecules, 2011, 44, 4057-4064.

56 A. Levy and M. Litt, J. Polym. Sci., 1968, 6, 1883-1894.

57 P. J. M. Bouten, K. Lava, J. C. M. van Hest and R. Hoogenboom, Polymers, 2015, 7, 1998-2008.

58 N. S. Ieong, M. Hasan, D. J. Phillips, Y. Saaka, R. K. O'Reilly and M. I. Gibson, Polym. Chem., 2012, 3, 794-799.

59 Q. L. Zhang, L. Voorhaar, S. K. Filippov, B. F. Yesil and R. Hoogenboom, J. Phys. Chem. B, 2016, 120, 4635-4643.

60 E. Djokpé and W. Vogt, Macromol. Chem. Phys., 2001, 202, $750-757$.

61 L. Starovoytova, J. Spěváček, L. Hanyková and M. Ilavský, Polymer, 2004, 45, 5905-5911.

62 T. J. Li, H. Tang and P. Y. Wu, Soft Matter, 2015, 11, 30463055.

63 W. Zhang, X. Chen and M. Zhang, Polym. Bull., 2014, 71, 243-260.

64 B. Trzebicka, E. Haladjova, Ł. Otulakowski, N. Oleszko, W. Wałach, M. Libera, S. Rangelov and A. Dworak, Polymer, 2015, 68, 65-73.

65 A. El Asmar, O. Gimello, G. Morandi, D. Le Cerf, V. Lapinte and F. Burel, Macromolecules, 2016, 49, 4307-4315.

66 J.-S. Park and K. Kataoka, Macromolecules, 2006, 39, 66226630.

67 M. Glassner, K. Lava, V. R. de la Rosa and R. Hoogenboom, J. Polym. Sci., Part A: Polym. Chem., 2014, 52, 3118-3122. 
68 S. Huber and R. Jordan, Colloid Polym. Sci., 2008, 286, 395-402.

69 H. M. L. Lambermont-Thijs, R. Hoogenboom, C.-A. Fustin, C. Bomal-D'Haese, J.-F. Gohy and U. S. Schubert, J. Polym. Sci., Part A: Polym. Chem., 2009, 47, 515-522.

70 N. Zhang, R. Luxenhofer and R. Jordan, Macromol. Chem. Phys., 2012, 213, 1963-1969.

71 G. Le Fer, C. Amiel and G. Volet, Eur. Polym. J., 2015, 71, 523-533.

72 M. Hartlieb, D. Pretzel, C. Engert, M. Hentschel, K. Kempe, M. Gottschaldt and U. S. Schubert, Biomacromolecules, 2014, 15, 1970-1978.

73 J. C. Rueda, M. Asmad, V. Ruiz, H. Komber, S. Zschoche and B. Voit, Des. Monomers Polym., 2015, 18, 761769.

74 M. A. Boerman, H. L. van der Laan, J. Bender, R. Hoogenboom, J. A. Jansen, S. C. Leeuwenburgh and J. C. M. Van Hest, J. Polym. Sci., Part A: Polym. Chem., 2016, 54, 1573-1582.

75 M. A. Mees and R. Hoogenboom, Macromolecules, 2015, 48, 3531-3538.

76 A. Gress, A. Völkel and H. Schlaad, Macromolecules, 2007, 40, 7928-7933.

77 C. Diehl and H. Schlaad, Chem. - Eur. J., 2009, 15, 1146911472.

78 C. Diehl and H. Schlaad, Macromol. Biosci., 2009, 9, 157161.

79 K. Kempe, R. Hoogenboom and U. S. Schubert, Macromol. Rapid Commun., 2011, 32, 1484-1489.

80 K. Kempe, T. Neuwirth, J. Czaplewska, M. Gottschaldt, R. Hoogenboom and U. S. Schubert, Polym. Chem., 2011, 2, 1737-1743.

81 T. R. Dargaville, K. Lava, B. Verbraeken and R. Hoogenboom, Macromolecules, 2016, 49, 4774-4783.

82 A. Sehlinger, B. Verbraeken, M. A. R. Meier and R. Hoogenboom, Polym. Chem., 2015, 6, 3828-3836.

83 M. Hruby, S. K. Filippov, J. Panek, M. Novakova, H. Mackova, J. Kucka, D. Vetvicka and K. Ulbrich, Macromol. Biosci., 2010, 10, 916-924.

84 J. H. Kim, E. Lee, J. S. Park, K. Kataoka and W. D. Jang, Chem. Commun., 2012, 48, 3662-3664.

85 E. V. Korchagina, X. P. Qiu and F. M. Winnik, Macromolecules, 2013, 46, 2341-2351.

86 L. T. T. Trinh, H. M. L. Lambermont-Thijs, U. S. Schubert, R. Hoogenboom and A. L. Kjoniksen, Macromolecules, 2012, 45, 4337-4345.

87 R. Takahashi, T. Sato, K. Terao, X. P. Qiu and F. M. Winnik, Macromolecules, 2012, 45, 6111-6119.

88 R. Takahashi, X. P. Qiu, N. Xue, T. Sato, K. Terao and F. M. Winnik, Macromolecules, 2014, 47, 6900-6910.

89 H. M. L. Lambermont-Thijs, H. P. C. Van Kuringen, J. P. W. Van der Put, U. S. Schubert and R. Hoogenboom, Polymers, 2010, 2, 188-199.

90 C. Diehl, I. Dambowsky, R. Hoogenboom and H. Schlaad, Macromol. Rapid Commun., 2011, 32, 1753-1758.
91 R. Hoogenboom, H. M. L. Thijs, M. W. M. Fijten, B. M. van Lankvelt and U. S. Schubert, J. Polym. Sci., Part A: Polym. Chem., 2007, 45, 416-422.

92 R. Hoogenboom, H. M. L. Lambermont-Thijs, M. J. H. C. Jochems, S. Hoeppener, C. Guerlain, C.-A. Fustin, J.-F. Gohy and U. S. Schubert, Soft Matter, 2009, 5, 35903592.

93 O. Sedlacek, P. Cernoch, J. Kucka, R. Konefal, P. Stepanek, M. Vetrik, T. P. Lodge and M. Hruby, Langmuir, 2016, 32, 6115-6122.

94 S. Osawa, K. Osada, S. Hiki, A. Dirisala, T. Ishii and K. Kataoka, Biomacromolecules, 2016, 17, 354-361.

95 N. Toncheva, C. Tsvetanov, S. Rangelov, B. Trzebicka and A. Dworak, Polymer, 2013, 54, 5166-5173.

96 A. Antunes, M. Dierendonck, G. Vancoillie, J. P. Remon, R. Hoogenboom and B. G. De Geest, Chem. Commun., 2013, 49, 9663-9665.

97 J. X. An, A. Dedinaite, F. M. Winnik, X. P. Qiu and P. M. Claesson, Langmuir, 2014, 30, 4333-4341.

98 A. Dworak, A. Utrata-Wesolek, N. Oleszko, W. Walach, B. Trzebicka, J. Aniol, A. L. Sieron, A. Klama-Baryla and M. Kawecki, J. Mater. Sci.: Mater. Med., 2014, 25, 11491163.

99 N. Oleszko, W. Walach, A. Utrata-Wesolek, A. Kowalczuk, B. Trzebicka, A. Klama-Baryla, D. Hoff-Lenczewska, M. Kawecki, M. Lesiak, A. L. Sieron and A. Dworak, Biomacromolecules, 2015, 16, 2805-2813.

100 O. Koshkina, T. Lang, R. Thiermann, D. Docter, R. H. Stauber, C. Secker, H. Schlaad, S. Weidner, B. Mohr, M. Maskos and A. Bertin, Langmuir, 2015, 31, 8873-8881.

101 V. R. de la Rosa, W. M. Nau and R. Hoogenboom, Org. Biomol. Chem., 2015, 13, 3048-3057.

102 V. R. de la Rosa, W. M. Nau and R. Hoogenboom, Int. J. Mol. Sci., 2015, 16, 7428-7444.

103 V. R. de la Rosa and R. Hoogenboom, Chem. - Eur. J., 2015, 21, 1302-1311.

104 J. H. Kim, D. Yim and W. D. Jang, Chem. Commun., 2016, 52, 4152-4155.

105 J. H. Kim, Y. Jung, D. Lee and W. D. Jang, Adv. Mater., 2016, 28, 3499-3503.

106 V. R. de la Rosa, Z. Y. Zhang, B. G. De Geest and R. Hoogenboom, Adv. Funct. Mater., 2015, 25, 2511-2519.

107 J. H. Kim, E. Koo, S. Y. Ju and W. D. Jang, Macromolecules, 2015, 48, 4951-4956.

108 C. Fetsch, A. Grossmann, L. Holz, J. F. Nawroth and R. Luxenhofer, Macromolecules, 2011, 44, 6746-6758.

109 J. W. Robinson, C. Secker, S. Weidner and H. Schlaad, Macromolecules, 2013, 46, 580-587.

110 J. W. Robinson and H. Schlaad, Chem. Commun., 2012, 48, 7835-7837.

111 M. W. Thielke, C. Secker, H. Schlaad and P. Theato, Macromol. Rapid Commun., 2016, 37, 100-104.

112 C. Secker, A. Völkel, B. Tiersch, J. Koetz and H. Schlaad, Macromolecules, 2016, 49, 979-985.

113 X. Tao, Y. Deng, Z. Shen and J. Ling, Macromolecules, 2014, 47, 6173-6180. 
114 X. Tao, J. Du, Y. Wang and J. Ling, Polym. Chem., 2015, 6, 3164-3174.

115 S. H. Lahasky, X. Hu and D. Zhang, ACS Macro Lett., 2012, 1, 580-584.

116 S. H. Lahasky, L. Lu, W. A. Huberty, J. Cao, L. Guo, J. C. Garno and D. Zhang, Polym. Chem., 2014, 5, 14181426.

117 S. Xuan, C.-U. Lee, C. Chen, A. B. Doyle, Y. Zhang, L. Guo, V. T. John, D. Hayes and D. Zhang, Chem. Mater., 2016, 28, 727-737.

118 T. J. Deming, Prog. Polym. Sci., 2007, 32, 858-875.

119 N. Hadjichristidis, H. Iatrou, M. Pitsikalis and G. Sakellariou, Chem. Rev., 2009, 109, 5528-5578.

120 E. R. Wright and V. P. Conticello, Adv. Drug Delivery Rev., 2002, 54, 1057-1073.

121 C. M. Chopko, E. L. Lowden, A. C. Engler, L. G. Griffith and P. T. Hammond, ACS Macro Lett., 2012, 1, 727731.

122 Y. Wu, Y. Deng, Q. Yuan, Y. Ling and H. Tang, J. Appl. Polym. Sci., 2014, 131, 1097-4628.

123 A. Kapetanakis and A. Heise, Eur. Polym. J., 2015, 69, 483489.

124 C. Xiao, Y. Cheng, Y. Zhang, J. Ding, C. He, X. Zhuang and X. Chen, J. Polym. Sci., Part A: Polym. Chem., 2014, 52, 671-679.
125 Y. Xu, M. Zhu, M. Li, Y. Ling and H. Tang, Polym. Chem., 2016, 7, 1922-1930.

126 Y. Deng, Y. Xu, X. Wang, Q. Yuan, Y. Ling and H. Tang, Macromol. Rapid Commun., 2015, 36, 453-458.

127 J. Y. Yuan and M. Antonietti, Polymer, 2011, 52, 1469-1482.

128 Y. J. Men, H. Schlaad and J. Y. Yuan, ACS Macro Lett., 2013, 2, 456-459.

129 Y. Yang, Y. Wu, R. Li, Y. Ling and H. Tang, Aust. J. Chem., 2016, 69, 112-118.

130 J. Shen, C. Chen, W. Fu, L. Shi and Z. Li, Langmuir, 2013, 29, 6271-6278.

131 D.-L. Liu, X. Chang and C.-M. Dong, Chem. Commun., 2013, 49, 1229-1231.

132 J. X. Ding, C. S. Xiao, Z. H. Tang, X. L. Zhuang and X. S. Chen, Macromol. Biosci., 2011, 11, 192-198.

133 J. Ding, L. Zhao, D. Li, C. Xiao, X. Zhuang and X. Chen, Polym. Chem., 2013, 4, 3345-3356.

134 Y. Shen, S. Desseaux, B. Aden, B. S. Lokitz, S. M. Kilbey, Z. Li and H.-A. Klok, Macromolecules, 2015, 48, 2399-2406.

135 X. Fu, Y. Shen, W. Fu and Z. Li, Macromolecules, 2013, 46, 3753-3760.

136 E. G. Gharakhanian and T. J. Deming, J. Phys. Chem. B, 2016, 120, 6096-6101.

137 J. Yan, K. Liu, W. Li, H. Shi and A. Zhang, Macromolecules, 2016, 49, 510-517. 